Florida International University FIU Digital Commons

6-22-2018

\title{
Impact of a Nutrition and Yoga Intervention in Breast Cancer Suvivors' Quality of Life
}

Tammy C. Fogarty

touel001@fiu.edu

DOI: $10.25148 /$ etd.FIDC006869

Follow this and additional works at: https://digitalcommons.fiu.edu/etd

Part of the Dietetics and Clinical Nutrition Commons

\section{Recommended Citation}

Fogarty, Tammy C., "Impact of a Nutrition and Yoga Intervention in Breast Cancer Suvivors' Quality of Life" (2018). FIU Electronic Theses and Dissertations. 3766.

https://digitalcommons.fiu.edu/etd/3766

This work is brought to you for free and open access by the University Graduate School at FIU Digital Commons. It has been accepted for inclusion in FIU Electronic Theses and Dissertations by an authorized administrator of FIU Digital Commons. For more information, please contact dcc@fiu.edu. 


\section{FLORIDA INTERNATIONAL UNIVERSITY \\ Miami, Florida}

IMPACT OF A NUTRITION AND YOGA INTERVENTION IN BREAST CANCER SURVIVORS' QUALITY OF LIFE

A dissertation submitted in partial fulfillment of the requirements for the degree of DOCTOR OF PHILOSOPHY in DIETETICS AND NUTRITION by

Tammy Fogarty 
To: Dean Tomás R. Guilarte

Robert Stempel College of Public Health and Social Work

This dissertation, written by Tammy Fogarty, and entitled Impact of a Nutrition and Yoga Intervention in Breast Cancer Survivors' Quality of Life, have been approved in respect to style and intellectual content, and is referred to you for judgement.

We have read this dissertation and recommend that it be approved.

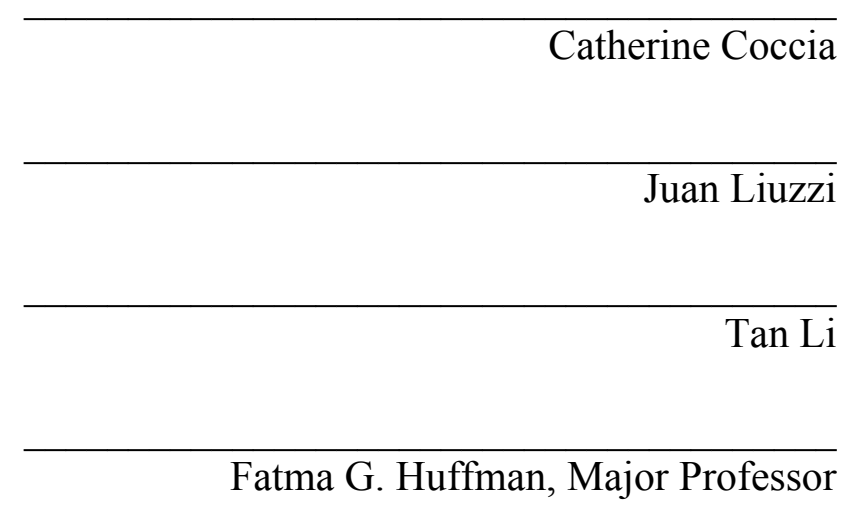

Date of Defense: June 29, 2018

The dissertation of Tammy Fogarty is approved.

Dean Tomás R. Guilarte Robert Stempel College of Public Health and Social Work

Andres G. Gil Vice President for Research and Economic Development and Dean of the University Graduate School

Florida International University, 2018 


\section{DEDICATION}

I dedicate this dissertation to my husband, Robert Fogarty. Because of his unconditional love, support, encouragement, and sacrifices this work became completed.

I dedicated this dissertation to my closest family and friends who have continually provided encouragement, motivation, and support throughout this journey. 


\section{ACKNOWLEDGMENTS}

I would like to express my appreciation and heartfelt gratitude to my major professor and mentor, Dr. Fatma Huffman, whose motivation and guidance empowered me to work on research near and dear to my heart. Thank you for keeping me focused and believing in me. I would like to thank Dr. Catherine Coccia for brainstorming ideas and helping me formulate different topics for my research. I would like to thank Dr. Juan Liuzzi for his time and encouragement throughout the development of my research. I would like to thank Dr. Tan Li for his time and patience in providing me with statistical advice. A special thanks to Monica Schmidt-Kniskern for the unwavering support and graciously opening the doors of her yoga studio for this intervention. 


\section{ABSTRACT OF DISSESRTATION \\ IMPACT OF A NUTRITION AND YOGA INTERVENTION IN BREAST CANCER \\ SURVIVORS' QUALITY OF LIFE \\ by}

Tammy Fogarty

Florida International University, 2018

Miami, Florida

\section{Professor Fatma G. Huffman, Major Professor}

The aim of the present study was to determine if a nutrition and yoga intervention will improve quality of life (QoL) in breast cancer survivors (BCS). Using the Transactional Model of Stress and Coping as a guide to lead the intervention, the intervention assessed potential barriers, self-efficacy, diet quality, and physical activity as it relates to quality of life. Twenty-seven women were enrolled in the study and randomly assigned to the control or intervention group. The intervention consisted of 6-weeks of yoga classes and 6-weeks of online nutrition education. The control group received a nutrition consultation and nutrition guidelines from the American Cancer Society. Measurement of variables was conducted at baseline, post-intervention (6 weeks), and follow-up (12 weeks). Oneway repeated measures ANOVA, paired samples t-test, and post hoc analysis with Bonferroni adjustment was used to analyze the data. Mediation analysis with regression was performed to demonstrate the effect the intervention had on quality of life. The intervention elicited a statistically significant difference in the Total Outcome Index quality of life score from baseline to post-intervention $(P<.005)$ and from baseline to follow-up $(P<.005)$ in the intervention group. The frequency of how often fruits and 
vegetables were consumed was significant between time points, $(P<.05)$, but not between the control and intervention group, $P=.538$. The amount of fruit and vegetables consumed each time was statistically significant for the intervention group from baseline to post-intervention $(P<.05)$ however there was no significant difference from baseline to follow-up $(P=.067)$. There was no difference between the control and intervention group, $(P=.216)$. There was a statistically significant difference for physical activity for time $(P<.005)$ but not between groups $(P=.166)$ however the intervention group has a statistically significant difference between baseline and post-intervention $(P<.005)$ but not between baseline and follow-up, $(P=.082)$. We cannot confidently predict that participant's quality of life scores are determined by group with the help of mediators after conducting a mediation analysis with regression. A six-week nutrition and yoga intervention in BCS elicited significant changes in QoL in BCS. Even though the results did not show significant changes between the control and intervention group there were significant changes within the intervention group from baseline to post-intervention and baseline to follow-up which may indicate a 6-week online nutrition education program coupled with a 6-week yoga intervention an effective tool to improve QoL in BCS. 


\section{TABLE OF CONTENTS}

CHAPTER

PAGE

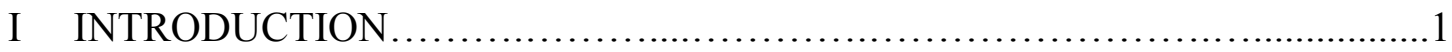

Cancer Related Co-morbidities..............................................

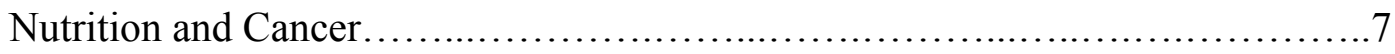

Dietary Guidelines for Cancer Prevention.......................................13

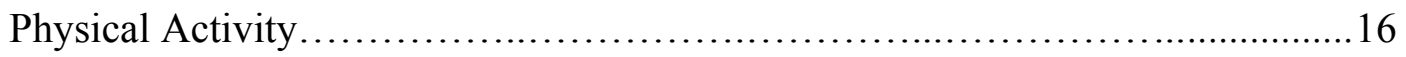

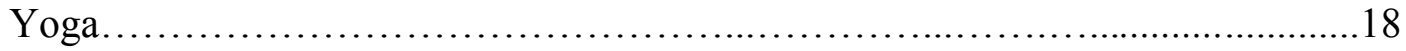

Transactional Model of Stress and Coping........................................21

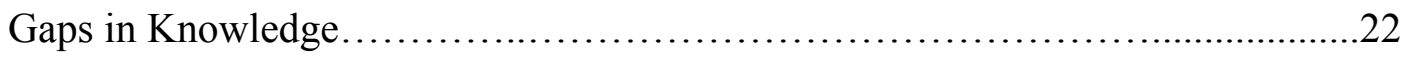

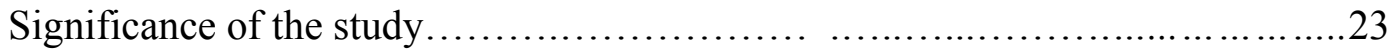

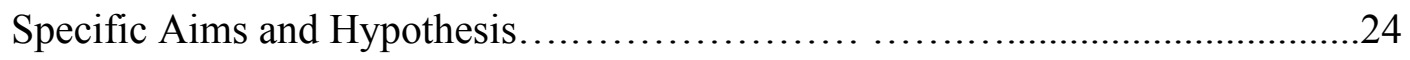

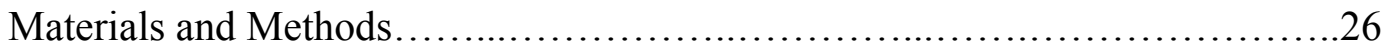

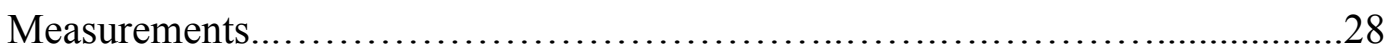

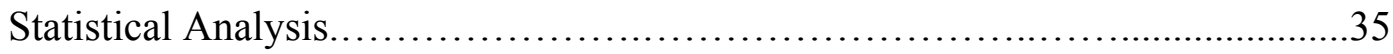

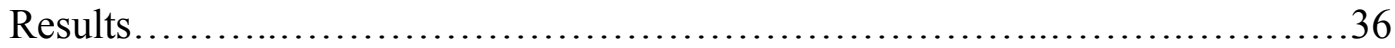

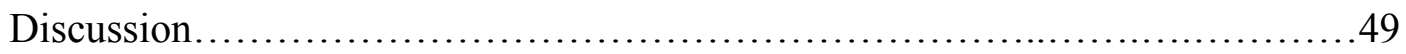

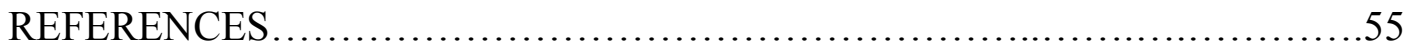

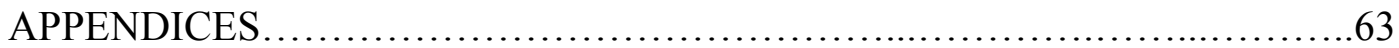

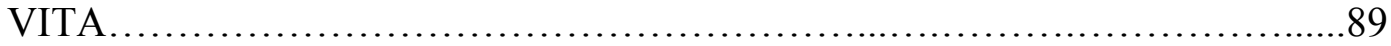




\section{CHAPTER I: INTRODUCTION}

An estimated one in eight women will develop breast cancer (BC) in her lifetime (Howlader et al., 2015; Ferlay et al., 2010) and as of January 2014, more than 3.1 million women have been diagnosed with breast cancer (American Cancer Society, 2015). A greater comprehension of disease etiology and risks have led to improved screening tools for early detection and the development of highly effective, targeted therapies to treat BC. Early detection and improved therapies have resulted in $99 \%$ survival rates for early stage $\mathrm{BC}$ in non-Hispanic white women with an average 5, 10, and 15-year survival rates of $89 \%, 82 \%$, and $77 \%$ respectively (American Cancer Society, 2015). Excess body weight, poor diet quality, and physical inactivity are common among breast cancer survivors (BCS) with over $60 \%$ being overweight or obese, $60 \%$ insufficiently active, and over $80 \%$ of BCS consuming inadequate amounts of fruits and vegetables (Reeves et al, 2016). These factors are associated with poor health outcomes and an increased risk of co-morbidities associated with BC treatment. The increased survival rates of women diagnosed with $\mathrm{BC}$ have resulted in an increasing population of breast cancer survivors (BCS), all with unique dietary and quality of life concerns.

Breast cancer is the most commonly diagnosed cancer in women (Cancer Facts \& Figures, 2015) and the second leading cause of cancer death (Siegel, Ma, Zou, \& Jemal, 2014). An estimated 231,840 new cases of invasive breast cancer and an estimated 60,290 cases of in situ breast cancer were diagnosed in 2015 (American Cancer Society, 
2015). BC rates have reduced by 36\% from 1989 to 2012 (American Cancer Society, 2016) and cancer survival rates have improved with $89.4 \%$ of women surviving at least five years (Howlander et al., 2015). Risk factors for breast cancer include family history, age, obesity, hormone therapy, birth control use, physical inactivity, tobacco use, and diet (American Cancer Society, 2016, Thomson, 2012). The most modifiable risk factor for $\mathrm{BC}$ risk is diet with about one-third of breast cancer related deaths attributed to diet and physical activity behaviors, including overweight and obesity (Kushi et al., 2012). Healthy lifestyle and dietary choices have been associated with a lower incidence of BC (Chlebowski, 2013) however current research suggests that women at higher risk for BC are not more likely to adhere to dietary and lifestyle changes (Bostean, Crespi, \& McCarthy, 2013).

\section{$\underline{\text { Cancer Related Co-morbidities }}$}

Cancer survivors frequently experience treatment-related side effects which often continue after the completion of treatment. Survivors commonly report pain, anxiety, depression, fatigue, and lymphedema (Sadja \& Mills, 2013). These long-term effects, often called late-effects, are a series of complications that begin either shortly after the start of treatment or years later resulting in persistent effects on cardiovascular, musculoskeletal, nervous, endocrine, and immune systems (Schmitz et al., 2010). These long-term effects can be exacerbated from existing co-morbidities prior to a cancer diagnosis. 
Cardiovascular Disease. As the survival rates from BC continues to rise, so does the risk of cardiovascular disease. Cancer related therapies, particularly anthracycline chemotherapy, left-sided radiation, and trastuzumab therapy, are associated with cardiotoxicities (Kirkham \& Davis, 2015). Cancer therapies, including chemotherapy, radiation, and surgery have been shown to impact cardiovascular health making cardiovascular disease the leading cause of death in older women with BC (Patnaik, 2011). Physical activity is effective in the prevention of primary and secondary cardiovascular disease however only a small percentage of BCS are physically active before, during, or after BC treatments (Parma et al., 2015). The mechanism in which physical activity may prevent cardiotoxicity is through its antioxidant effects to decrease reactive oxygen species (ROS). Cells are equipped with an endogenous antioxidant system to protect against ROS in the liver and other tissues, however the cardiomyocytes have one fourth of the antioxidant capacity making it more vulnerable to oxidative damage (Ascensão, 2006). In animal studies, exercise trained rodents have increased levels of antioxidant capacity that may prevent damage to the heart from ROS (Ashrafi, Roshan, Mahjoub, 2012). Additional co-morbidities associated with cardiovascular disease include hypertension, hyperlipidemia, diabetes, and obesity, which may affect overall survival resulting in an increased incidence of mortality due to cardiovascular disease (Bodai \& Tuso, 2015).

A study conducted by Weaver et al., (2013) assessed the prevalence of CVD risk factors among 1,582 long-term cancer survivors compared to survey data from the general population in the same geographic region. They found that cardiovascular risk 
factors such as obesity, physical inactivity, diabetes, hypertension, and hypercholesterolemia were more common among cancer survivors. Similarly, in a study conducted by Buttros et al. (2013), researchers assessed the risk of metabolic syndrome in postmenopausal BCS as compared to postmenopausal women never diagnosed with cancer. The study found $46.2 \%$ of BCS were obese as compared with controls. Metabolic Syndrome was diagnosed in $50 \%$ of BCS as compared to $37.5 \%$ of women in the control group $(P<0.05)$. Research has demonstrated that pre-existing and chronic conditions, as well as co-morbidities associated with $\mathrm{BC}$ treatments, have significant effects on the overall survival of BCS (Patnaik, Byers, DiGuiseppi, Dabelea, \& Denberg, 2011).

Obesity. Obesity is attributed to $15 \%$ to $20 \%$ of total cancer related mortality (American Cancer Society, 2015) and there is increasing evidence correlating obesity to elevated risk, recurrence, and cancer related mortality in individuals diagnosed with early stage breast cancer (Ligibel et al., 2014). Based on epidemiological studies regarding diet and the incidence of $\mathrm{BC}$, the only strong, reproducible, and statistically significant associations are alcohol intake, weight gain, overweight, and obesity (Ferrini, Ghelfi, Mannucci, \& Titta, 2015; Weisman, 2012). Obesity affects cancer survival a number of different ways including altering insulin resistance pathway, increasing levels of adipokines, and decreasing adiponectin which interacts with estrogen receptors (Brenner et al., 2016). High-fat diets are associated with increased body adiposity (Wang \& DuBois, 2010) resulting in hyperinsulinemia, increased adipokine secretion, elevated production of reactive oxygen species (Sung, Yeon, Park, Park, \& Choi, 2011), and an increase in tumor necrosis factor alpha (TNF $\alpha)$ (Weichlaus, Broom, \& Bermano, 2011); 
all of which lead to chronic inflammation and tumor growth. In addition, elevated levels of insulin-like growth factor 1 (IGF-1) is commonly seen in overweight and obese women which may result in the proliferation of cancerous cells through the activation of targeted genes. (Renehan, Roberts, \& Dive, 2008). As a result, it has been concluded that dietary fats play an essential role in the etiology of BC and BC recurrence (Makarem, Chandran, Bandera, \& Parekh, 2013).

Chan, Vierira, Aune, et al., (2014) conducted a meta-analysis of 82 studies, including 200,000 women diagnosed with breast cancer, and found a $75 \%$ increase in mortality rates of premenopausal women and a $34 \%$ increase in mortality rates in postmenopausal women that were obese at time of diagnosis. In addition, obesity places individuals at greater risk of developing co-morbidities, specifically heart disease and diabetes (Johnson, Davis, Law, \& Sulpher, 2016), which may impact overall survival and potentially increase the risk of cancer recurrence. Obesity also contributes to healthrelated issues during treatment such as poor wound healing, post-operative infections, lymphedema, and interference with effective delivery of chemotherapies (Johnson, Davis, Law, \& Sulpher, 2016).

The NCI Surveillance, Epidemiology, and End Results (SEER) analysis indicated that if every adult reduced their BMI by 1 percent this would prevent the increase in the number of cancer cases and would result in fewer cases of new cancer each year (National Cancer Institute, 2012). The World Cancer Research Fund (WCRF) and the American Institute for Cancer Research (AICR) both support the data indicating BMI 
plays a significant role in cancer development. Maintenance of a healthy BMI throughout one's lifespan is one of the most important modifiable risk factor to protect against cancer and cancer recurrence (WCRF/AICR, 2007).

Fatigue. Approximately $33 \%$ of BCS report a decrease in normal activities due to fatigue (NCCN, 2016). Chronic fatigue may be a result of late effects, co-morbidities, and inflammation associated with $\mathrm{BC}$ treatment. Fatigue is one of the most commonly reported side effects described by BCS and can have long-term consequences. The National Comprehensive Cancer Network has defined cancer related fatigue as a "distressing, persistent, subjective sense of physical, emotional, and/or cognitive tiredness or exhaustion related to cancer or cancer-related treatment that is not proportional to recent activity and interferes with usual functioning" (NCCN, 2016). Fatigue can be a debilitating side effect directly impacting quality of life for BCS.

Today, women can expect long-term survival due to targeted therapies however quality of life may be affected by late-effect symptoms of treatment, premature menopause (Ganz, 2005), poor body image, fatigue, infertility, and the risk of recurrence (Howard-Anderson et al., 2011). Due to the increasing population of BCS more attention has been given to quality of life after diagnosis and during and after treatment. Quality of life is described as how an individual subjectively measures the "goodness" of multiple aspects of their life including physical, functional, emotional, and social well-being (Denmark-Wahnefried et al., 2015). The Exercise and Nutrition Enhance Recovery and Good Health for You (ENERGY) trial to determine quality of life outcomes among BCS 
in a 24-month nutrition and exercise intervention. All participants received written materials and weight loss counseling based on dietary and physical activity guidelines from the American Cancer Society (ACS). The intervention group received an intensive intervention consisting of a group-based, semi-structured weight loss program including telephone counseling and tailored newsletters. Study results demonstrated improvements in vitality in both groups initially however over time depressive symptoms increased in the intervention group. At 24-months concluding intervention an increased QOL was evident on a short term basis however long term data suggested that the effect of diet and exercise interventions diminished over time (Denmark-Wahnefried et al., 2015).

\section{Nutrition and Cancer}

Diet is thought to play an essential role in overall cancer risk therefore dietary and physical activity guidelines have been established by the American Cancer Society (ACS) and the World Cancer Research Fund (WCRF) in conjunction with the American Institute for Cancer Research (AICR). The ACS and WCRF/AICR established guidelines based on current epidemiological research of the associations between various dietary factors and the risk for BC (WCRF/AICR, 2007). Based on empirical evidence, alcohol and diet exposure are consistently associated with increased risk for $\mathrm{BC}$ and $\mathrm{BC}$ recurrence and weight gain during adulthood, current body fat, and obesity were also associated with an increased risk for $\mathrm{BC}$, although primarily in postmenopausal women (Thomson, 2015). 
Dietary choices and weight management play a significant role in overall cancer risk and numerous nutrition interventions have been published with varying results and recommendations; however healthy lifestyle choices are consistently associated with a decreased risk of BC (Thomson, 2015). A study conducted by Christifano, Fazzino, Sullivan, \& Befort (2016) conducted a six-month weight management intervention in 180 overweight/obese BCS. The aim of the study was to examine the change in diet quality and to determine if diet quality is an important factor related to weight loss. Diet quality was assessed using the Healthy Eating Index (HEI)-2010. After a 6-month intervention, participants significantly improved diet quality $(\mathrm{P}=0.001)$ and lost $13.2 \pm 5.8 \%$ (mean \pm $\mathrm{SD})$ of body weight $(\mathrm{P}=0.001)$. Controlling for $\mathrm{BMI}$ at baseline, it was determined HEI score was significantly associated with weight loss $(\mathrm{P}=0.003)$. The findings of this intervention support diet quality is predictive of weight loss. A similar study conducted by Finocchario et al., (2016) looked at the effects of a nutrition intervention on dietary change and weight loss in BCS. The study included a four-week nutrition intervention based on the WCRF/AICR dietary guidelines modelled on the Mediterranean diet with follow-up at two and six months to monitor adherence to lifestyle changes. One hundred participants were enrolled. The intervention resulted in a $2.8 \%$ and $4.2 \%(\mathrm{p}<.001)$ reduction in weight loss after two and six-month follow-up. The study did not include a physical activity component in the intervention however subjects did decrease sedentary habits that may have contributed to overall weight loss. Physical activity improved over the duration of the study with $64 \%$ of women reported as inactive at baseline compared to $33 \%$ of women reporting inactive lifestyles at the completion of the study. 
Alcohol. Evidence suggests that alcohol increases the risk of breast cancer, regardless of the type of alcohol consumed. The Women's Health Initiative (WHI) observational study cohort of 87,724 postmenopausal women found that one alcoholic beverage daily was associated with an $82 \%$ greater risk for hormone receptor positive $\mathrm{BC}$ (Li et al., 2010). A recent review of literature conducted by Cao and Giovannucci (2016) concluded heavy alcohol intake to be linked to several different types of cancer, included $\mathrm{BC}$, however light alcohol consumption (one drink per day for women) is not significantly associated with cancer risk and may be beneficial for cardiovascular disease; BCS should not exceed more than one drink per day.

Dietary Fat. The role of dietary fat in $\mathrm{BC}$ has been vastly studied and epidemiological evidence suggests dietary fat to be associated with the risk of BC. A meta-analysis of 57 studies conducted by Turner (2011) indicated the type of fat may have the greatest influence on $\mathrm{BC}$ risk. Polyunsaturated and saturated fats were associated with an increased risk of $\mathrm{BC}$ in postmenopausal women, and monounsaturated fats did not show a significant association in $\mathrm{BC}$ risk. Eating patterns also play a role in the risk of $\mathrm{BC}$ and $\mathrm{BC}$ recurrence. A high-fat eating pattern, with greater than $40 \%$ of total calories coming from saturated fats is associated with a 2-fold greater risk for $\mathrm{BC}$ (Schulz et al., 2008). Alternatively, low-fat diets play a role in weight maintenance and reducing weight gain associated with age, thus indirectly decreasing the risk of $\mathrm{BC}$.

The Women's Intervention Nutrition Study (WINS), conducted by Chlebowski et al., (2006) enrolled 2,437 women with early stage breast cancer to receive dietary 
intervention to reduce total fat intake. The primary objective of the study was relapse-free survival by reducing the percentage of calories from fat to $15 \%$ while maintaining nutritional adequacy. Women enrolled to the control group received a low-fat eating plan with individual fat gram goals based on energy intake to maintain weight. The participants received eight in-person nutrition counseling sessions and subsequent contact with a dietitian every three months for one year. The control group received standardized written information on general dietary guidelines and one in-person session with a dietitian at baseline regarding nutrition adequacy for vitamin and mineral intake, as well as contacts with a dietitian every three months for one year. The results indicated a statistically significant reduction in dietary fat intake from $29.9 \%$ to $20.3 \%(\mathrm{P}<0.0001)$ in the intervention group. The reduced dietary fat intake was maintained after a 60-month follow-up resulting in an average weight loss of six pounds (HR 0.76, 95\% CI 0.60-0.98, $\mathrm{P}=0.03$ ). Additionally, there were 277 relapse-free survival events and 389 disease-free survival events reported after 60-month follow-up. The hazard ratio of an event in the intervention group compared to the control was $0.76(95 \% \mathrm{CI}=0.60$ to $0.98, \mathrm{P}=.077$ for stratified $\log$ rank and $\mathrm{P}=.034)$.

The Women's Health Initiative Randomized Controlled Dietary Modification Trial (WHI) conducted a similar intervention following a low fat dietary pattern in an effort to reduce breast cancer risk in 48,835 postmenopausal women aged 50-79 years, without a history of BC. The participants were randomized into the low-fat diet ( $20 \%$ of total energy) or usual dietary fat intake group. The low fat diet group received diet education by attending monthly, then quarterly, group class led by a registered dietitian 
for four years. Behavioral change was promoted by providing motivational interviewing, cognitive behavioral therapy, and group social support. The results of the study indicate that a low-fat dietary pattern did not result in a statistically significant reduction in invasive breast cancer risk over an 8.1-year follow-up (Prentice et al., 2006). A similar trial conducted by Martin et al., (2011) studied the primary prevention of BC in pre-and postmenopausal women at increased risk for $\mathrm{BC}$ due to high breast density. The randomized trial enrolled 4,690 women and followed them for 7-10 years. As in the previous study, this study assigned participants into a low-fat group or usual dietary fat group, and also found no significant differences in invasive breast cancer between the intervention and comparison group. However, a subgroup analysis determined greater baseline body weight and higher carbohydrate intake that were associated with a greater risk for estrogen receptor (ER) positive breast cancer (Martin et al., 2011). Both studies reviewed here recruited women without a history of breast cancer therefore dietary fat intake in the role of $\mathrm{BC}$ recurrence warrants further exploration.

Plant Based Foods. Plant based diet consisting of fruits, vegetables, whole grains, and legumes have been associated with weight maintenance however the relationship between plant based foods and reduced risk for $\mathrm{BC}$ has not been consistently demonstrated in epidemiological evidence (WCRF/AICR, 2007). Bioactive compounds found in plant based foods, such as isoflavones, phytic acid, and lycopene, are thought to promote health and decrease the risk of $\mathrm{BC}$ through antioxidant, anti-inflammatory, and estrogen-modulating effects (Thomson, 2015). The ACS encourages plant based diets with at least 2.5 servings of fruits and vegetables daily (American Cancer Society, 2015). 
A review of literature did not produce any recent studies regarding the effect of a diet solely based on plant based foods and the association of $\mathrm{BC}$ and $\mathrm{BC}$ recurrence. However, previous studies have demonstrated a reduction of dietary fat, in conjunction with increased vegetable consumption, reduces the risk for breast cancer recurrence (Rock et al., 1997).

Women's Healthy Eating and Living (WHEL) by Pierce et al., (2007) chose a dietary intervention aimed at increasing fruit, vegetable, and fiber consumption while decreasing fat intake to $15-20 \%$ of calories in BCS. After a six-year follow-up, there was an increase in fruit and vegetable intake however dietary fat intake remained consistent with reported amounts at baseline. Weight change did not occur as a result of this dietary intervention. The study concluded that the intervention had no effect on breast cancer incident. A prospective cohort study conducted by Makarem, Lin, Bandera, Jacques, and Parekh (2015) evaluated the associations between healthful behaviors, consistent with the WCRF/AICR cancer prevention guidelines and obesity-related risk. The study consisted of 2,983 adults from the Framingham Offspring cohort from 1991-2008. Data included diet, anthropometric measures, and physical activity. The results demonstrated, for every unit increment decrease in the alcohol score, there was a $29 \%$ lower risk of obesityrelated cancers (HR 0.71, 95\% CI 0.51-0.99) and a 49-71\% reduced risk of breast, prostate, and colorectal cancers. Additionally, every unit increment for plant based foods, was associated with a $66 \%$ reduced risk of colorectal cancer (HR 0.44$), 95 \%$ CI 0.22 0.88). Based on these findings, decreased alcohol intake and a plant-based diet is 
consistent with the cancer prevention guidelines to reduce the risk of obesity-related cancers.

\section{Dietary Guidelines for Cancer Prevention}

The World Cancer Research Fund/ American Institute for Cancer Research (WCRF/AICR) have established ten recommendations on diet, physical activity, and weight management for cancer prevention. These same guidelines are suggested to prevent recurrence of BC (American Institute of Cancer Research, 2016) and recent data suggests adherence to these guidelines is associated with a decreased incidence in $\mathrm{BC}$ (Hastert, Beresford, Patterson, Kristal, \& White, 2013; Romaguera et al., 2012). The recommendations are based on a comprehensive collection of data and include the following:

- Be as lean as possible without becoming underweight

- Be physically active for at least 30 minutes every day and limit sedentary habits

- Avoid sugary drinks and limit the consumption of energy dense foods

- Eat more of a variety of vegetables, fruits, whole grains, and legumes

- Limit consumption of red meats (beef, pork, lamb) and avoid processed meats

- If consumed at all, limit alcohol drinks to two for men and one for women per day

- Limit the consumption of salty foods and foods processed with sodium

- Don't use supplements to protect against cancer

- For breastfeeding women, it is best for mothers to breastfeed exclusively for up to six months and then add other liquids and foods 
- After treatment, cancer survivors should follow the recommendations for cancer prevention

The American Cancer Society (ACS) has established the Nutrition and Physical Activity Guidelines for Cancer Prevention. The guidelines are updated every five years based on current scientific research and is developed by a panel of experts in cancer research, prevention, epidemiology, public health, and policy. The ACS recommendations are consistent with other health organizations that have developed guidelines for various disease prevention including the American Heart Association, American Diabetes Association, 2010 Dietary Guidelines for Americans, 2008 Physical Activity Guidelines for Americans, and WCRF/AICR recommendations (Kushi et al., 2012). The 2012 ACS guidelines are as follows:

- Achieve and maintain a healthy weight throughout life

- Be as lean as possible throughout life without being underweight

- Avoid excess weight gain at all ages. For those who are currently overweight or obese, losing even a small amount of weight has health benefits and is a good place to start

- Engage in regular physical activity and limit consumption of high-calorie foods and beverages and beverages as key strategies for maintaining a healthy weight

- Adopt a physically active lifestyle

- Adults should engage in at least 150 minutes of moderate intensity or 75 minutes of vigorous intensity activity each week, or an equivalent combination, preferably spread throughout the week 
- Children and adolescents should engage in at least one hour of moderate or vigorous intensity activity each day, with vigorous intensity activity occurring at least three days each week

- Limit sedentary behavior such as sitting, lying down, watching television, or other forms of screen-based entertainment

- Doing some physical activity above usual activities, no matter what one's level of activity, can have many health benefits

- Consume a healthy diet, with an emphasis on plant foods

- Choose foods and beverages in amounts that help achieve and maintain a healthy weight

- Limit consumption of processed meat and red meat

- Eat at least 2.5 cups of vegetables and fruits each day

- Choose whole grains instead of refined grain products

- Drink no more than one alcoholic beverage per day for women or two per day for men

A study conducted by Catsburg, Miller, and Rohan (2014) investigated the association between $\mathrm{BC}$ risk and the adherence to the $\mathrm{ACS}$ and WCRF/AICR dietary recommendations. The study assessed dietary and lifestyle questionnaires of 49,613 women over a 16.6-year follow-up with 2,503 incident cases of BC. The study found that adherence to all six ACS guidelines was associated with a $31 \%$ reduction in $\mathrm{BC}$ as compared to women adhering to one guideline $(\mathrm{HR}=0.69 ; 95 \% \mathrm{CI}=0.49-0.97)$. Similarly, adherence to six to seven of the WCRF/AICR guidelines was associated with a $31 \%$ reduction in $\mathrm{BC}$ risk $(\mathrm{HR}=0.69 ; 95 \% \mathrm{CI}=0.47-1.00)$. The results suggest 
adherence to cancer prevention guidelines is associated with reduced BC risk and recurrence (Catsburg, Miller, \& Rohan, 2014). However, current data from lifestyle interventions indicate women at higher risk for $\mathrm{BC}$ are not more likely to adhere to dietary and lifestyle changes (Bostean, Crespi, \& McCarthy, 2013).

\section{Physical Activity}

Engaging in physical activity is an important behavior for BCS however a small percentage of BCS are active at levels consistent with physical activity guidelines (Parma et al., 2015). The benefits of exercise for BCS have been well documented and include improvements in physical functioning, fatigue, and emotional well-being (Schmitz et al., 2010) and is associated with a lower risk of invasive breast cancer in postmenopausal women (Ferrini et al., 2015; Goncalves, Florencio, and Maisonnet de Ataude, 2014). Additionally, physical activity may prevent tumor development by lowering hormone levels in premenopausal women, decrease levels of insulin and IGF-I, enhance immunity, and assist with weight management (National Institute of Health, 2009). Physical activity is consistently associated with a decreased risk of both $\mathrm{BC}$ incidence and $\mathrm{BC}$ recurrence and some studies have suggested the importance of timing of physical activity in relation to cancer diagnosis. A longitudinal study of 4,643 postmenopausal women diagnosed with invasive breast cancer after initial enrollment into the Women's Health Initiative study assessed physical activity from recreation and walking at baseline and three or six years after diagnosis for a follow-up visit. The study found that women participating in 9 MET-h/week or more of physical activity ( $~ 3 \mathrm{~h} /$ week of fast walking) before diagnosis had lower all-cause mortality $(\mathrm{HR}=0.61 ; 95 \% \mathrm{CI}, 0.44-0.87 ; \mathrm{P}=0.01)$ compared to 
inactive women. Women participating in $\geq 9 \mathrm{MET}-\mathrm{h} /$ week of physical activity after diagnosis had lower breast cancer mortality $(\mathrm{HR}=0.61 ; 95 \% \mathrm{CI}, 0.35-0.99 ; \mathrm{P}=0.49)$ and lower all-cause mortality $(\mathrm{HR}=0.54 ; 95 \% \mathrm{CI}, 0.38-0.79 ; \mathrm{P}<0.01)$. Women who increased or maintained physical activity of 9 or more MET-h/week after diagnosis had lower all-cause mortality $(\mathrm{HR}=0.67 ; 95 \% \mathrm{CI}, 0.46-0.96)$ even if they were inactive prior to diagnosis. The study concluded high levels of physical activity might improve survival in postmenopausal BCS (Irwin et al., 2011).

Studies have shown a decreased risk of $\mathrm{BC}$ recurrence and a decrease in $\mathrm{BC}$ specific mortality for BCS who are more physically active (Irwin et al., 2011, Ferrini et al., 2015). Regular physical activity is essential for BCS and despite these benefits being well documented, only a small percentage of cancer survivors are physically active at a level consistent with physical activity guidelines (Parma et al., 2015). A review of empirical evidence conducted by a panel of oncology experts (Schmitz et al., 2010) were in agreement regarding the safety and efficacy of exercise among cancer survivors. The review found consistent evidence that exercise is safe during and after cancer treatment and that regular physical activity improves aerobic fitness, muscular strength, and fatigue in $\mathrm{BCS}$. There was a consensus that resistance training can be safely performed by $\mathrm{BCS}$ experiencing, or at risk of, lymphedema. Additionally, the panel of experts concluded exercises, such as yoga, is considered safe in BCS as long as shoulder and arm morbidities are taken into consideration and exercises are modified to suit specific needs of BCS (Schmitz et al., 2010) 


\section{$\underline{\text { Yoga }}$}

Complementary alternative medicine (CAM) has gained significant attention in recent years for its potential benefit to improve quality of life, increase physical function, and enhance mental well-being (American Cancer Society, 2016). Mind-body therapies, a component of CAM, include meditation, guided imagery, and yoga. According to the World Health Organization, $70-80 \%$ of developed nations practice yoga as part of a healthy lifestyle. Yoga is derived from the Sanskrit word "yug", meaning to join, concentrate, or yoke. Yoga consists of eight limbs, knows as the yoga sutras, and includes: yama (ethical disciplines), niyama (individual observances), asana (poses), pranayama (breath), pratyahara (withdrawal of the senses), dharana (concentration), dhyana (meditation), and Samadhi (enlightenment) (Carrio, 2015). Yoga includes different styles such as hatha yoga, vinyasa, Bikram, Iyengar, and restorative yoga.

Yoga has been effective in reducing hypertension, decreasing inflammation associated with arthritis, and controlling diabetes (Sharma, Lingam, \& Nahar, 2016). The sole use of complementary alternative medicine (CAM) as a treatment for BC has not been established. However, yoga has been found to improve physical function, reduce pain, and decrease anxiety and depressive symptoms in women diagnosed with BC (Sudarshan, 2013). A study conducted by Rao et al, (2015) found yoga to be beneficial in lowering cancer-related stress, anxiety, depression, and mood disturbances. In a systemic review of literature conducted by Sharma, Lingam, \& Nahar (2016), 22 of 23 studies reviewed indicated statistically significant outcomes in yoga intervention studies including improved sleep, enhanced quality of life, reduced fatigue and related 
symptoms, improved menopausal symptoms, reduced body fat, and a reduction in depressive symptoms in BCS. In addition, yoga can be tailored and modified for individuals that have been sedentary, or experience pain and discomfort due to lymphedema, therefore providing a safe and effective method of physical activity that decreases fatigue, elevates mood, and improves sleep quality (Kiecolt-Glaser et al., 2014).

A randomized controlled trial by Bower et al., (2012) sought to determine the feasibility and efficacy of a 12-week Iyengar yoga intervention for BCS with persistent post treatment fatigue as compared to a health education control. The study results indicate that participants in the yoga group experienced significant reductions in fatigue and increased vigor from pre to post treatment that was sustained over three-month follow-up as compared to the control group. Another study conducted by Bower et al., (2014) hypothesized a twelve-week Iyengar yoga intervention would reduce inflammation-related gene expression and circulating markers of pro-inflammatory cytokine activity in cancer-induced fatigued BCS as compared to a control group receiving twelve-weeks of health education. The findings indicated that the yoga group had reduced activity of pro-inflammatory transcription factor nuclear factor kappa, increased activity of the anti-inflammatory glucocorticoid receptor, and reduced activity of cAMP response element binding protein (CREB) as compared to controls. All findings showed a significant difference $(\mathrm{p}<.05)$ between groups. Additionally, there was a significant effect in the soluble tumor necrosis factor receptor type II (sTNF-RII) and plasma levels of sTNF-RII remained stable in the yoga group however was found to be 
elevated in the control group $(\mathrm{p}=.028)$. There was no significant difference between groups for C-reactive protein, Interleukin 6 (IL-6), or diurnal cortisol (Bower et al., 2014). The findings of this study suggests yoga had beneficial effects on inflammatory markers in BCS with cancer-induced fatigue.

A similar RCT study conducted by Kiecolt-Glaser et al., (2014) examined yoga's impact on inflammation, specifically TNF $\alpha$, IL-6, IL-1 $\beta$, and C-reactive protein. After a 12 week trial the study results showed a reduction in IL-6 $(\mathrm{P}=.027), \mathrm{TNF} \alpha(\mathrm{P}=.027)$, and IL-1 $\beta(\mathrm{P}=.037)$ as compared to the control group that did not perform any physical activity. Additionally, the study also found decreased fatigue $(\mathrm{P}=.002)$ and improved vitality $(\mathrm{P}=.01)$ at 3-month follow-up (Kiecolt-Glaser et al., 2014). Conversely, a sixmonth study by Parma et al., (2015) sought to determine the effects of yoga on inflammatory markers and found significant reduction body fat $(-3.00 \%, d=-0.44, p<$ $.001)$ in BSC receiving yoga as compared to controls receiving conventional exercise and exercise of their choice. The study determined there were no significant changes in inflammatory markers including: serum IL-6, IL-8, Tumor necrosis factor alpha, and Creactive protein in BCS. However, this study had a small sample size and high attrition rate. Larger studies are necessary to determine optimal exercise protocols for BSC (Parma et al., 2015).

Approximately $33 \%$ of BCS report a decrease in normal activities due to fatigue. Chronic fatigue may be a result of late effects, co-morbidities, and inflammation associated with $\mathrm{BC}$ treatment. Fatigue is one of the most commonly reported side effects 
reported by BCS and can have long-term consequences (NCCN, 2016). Yoga has been shown to reduce fatigue, improve mood, and decrease inflammatory markers and the postures can be modified to accommodate physical limitations in BCS. Yoga has been shown to produce positive effects on physical energy and mental clarity, and thereby reduce levels of fatigue in BCS (Sadja \& Mills, 2013). Yoga intervention studies have shown positive results however many studies lack standardized approach to conducting yoga, varying duration of interventions, lack of behavioral theory models, variabilities in sample size, lack of power (Sharma, Lingam, \& Nahar, 2016), and patient-reported bias (Sadja \& Mills, 2013). Despite limitations in yoga intervention trials, yoga is a promising approach to integrative therapy for BCS and additional interventions utilizing yoga are necessary.

\section{$\underline{\text { Transactional Model of Stress and Coping }}$}

The Transactional Model of Stress and Coping developed by Lazarus and Folman (1987) focuses on the primary and secondary appraisal of a stressor. Primary appraisal is associated with a person's perception of an event as being trivial, a loss, a threat, or a challenge. The stressor perceived as a threat or challenge may create negative emotions affecting quality of life. The secondary appraisal is how an individual perceives their control over the stressor, such as self-efficacy and ability to make health decisions. An individual that does not feel in control over a potential outcome will likely experience decreased quality of life. In order to come to terms with a stressor an individual chooses appropriate coping mechanisms. Coping mechanisms vary with each individual however; 
the mechanism chosen will influence the outcome, such as health and well-being (Côté et al, 2009; Lazarus and Folman, 1987).

\section{$\underline{\text { Gaps in Knowledge }}$}

A review of literature conducted by Spark, Reeves, Fjeldsoe, and Eakin (2013) analyzed 1,298 publications pertaining to weight loss and physical activity interventions in BCS. Of the publications only 10 trials assessed post-intervention sustainability. Thus, there is a need to direct more attention to sustainability of nutrition and physical activity interventions in order to improve long-term health outcomes for the increasing population of BCS. In addition to sustainability there is a gap in the literature for dietary guidelines related to cancer recurrence and cardiotoxicity associated with breast cancer treatments. Current dietary guidelines from ACS are for cancer prevention however does not take into consideration the risks associated with heart disease. Plant based diets have been associated with a reduced risk of heart disease however effectively disseminating this information to BCS, in a method to promote long-term behavioral change, is necessary to reduce the risk for cancer recurrence and mortality associated with heart failure. Current dietary guidelines are vague and do not provide guidance toward portion sizes and nutrition knowledge such servings per day. Lastly, exercise recommendations to reduce the risk of oxidative damage causing heart disease is lacking. For survivors, physical activity is not just about weight management and more so about decreasing the risk of cardiac events. Dietary interventions do not focus on antioxidant intake to decrease the risk of both cancer recurrence and heart disease. 


\section{Significance of the Study}

Effective strategies, including nutrition and physical activity, to reduce the incidence of $\mathrm{BC}$ and cancer recurrence are essential. Despite great efforts of implementing diet and exercise interventions, little progress has been made due to the complicated nature associated with behavior change and lifestyle modifications. Randomized trials have demonstrated enhanced quality of life, less fatigue, improved body image, and decreased co-morbidities in individuals that have improved their dietary intake and increased physical activity during and after treatment for breast cancer. Nonetheless, despite the benefits demonstrated in nutrition and lifestyle intervention studies in cancer populations, cancer survivors are no more likely to consume a healthy diet, exercise, or maintain desirable body weight compared to adults without a history of cancer (Ligibel et al., 2014). Evidence has demonstrated that timing to motivate individuals to adopt healthy lifestyle behaviors is during a health event. Data from lifestyle interventions suggest necessary tools to achieve weight loss and increased physical activity are not readily available and oncologists have reported a lack of training and skills essential to initiate behavior change for their patients (Ligibel et al., 2014). Significant efforts are needed to educate and disseminate effective strategies to help BCS initiate and maintain healthy lifestyle changes post cancer treatment. Assessing outcomes for mortalities associated with $\mathrm{BC}$ and co-morbidities can assist health care providers and BCS in assessing appropriate dietary and lifestyle interventions.

Randomized controlled trials of yoga interventions suggest yoga has favorable effects on stress, anxiety, pain, fatigue, and depressive symptoms. Limitations of study 
design, sample size, and bias have been identified as the short comings (Parma et al., 2015). Even though nutrition interventions in BCS have resulted in weight loss, sustainability of weight loss continues to present challenges in this population (Travier et al., 2014).

With more than one-third of the world's adults being obese cardiovascular disease has become the leading cause of death in both men and women. A growing body of evidence suggests heart disease and cancer share similar risk factors related to poor dietary habits and sedentary lifestyle (Johnson, Davis, Law, \& Sulpher, 2016).

To our knowledge, a nutrition and yoga intervention trial in BCS to improve quality of life has not been conducted. The objective of this study is to determine if a nutrition and yoga intervention will improve QoL in BCS and secondary outcomes will determine if diet quality and physical activity levels improve throughout the intervention.

\section{Specific Aims and Hypothesis}

Specific Aim 1:

To determine if a nutrition and yoga intervention among breast cancer survivors will decrease perceived barriers to improve their health and increase self-efficacy.

Hypothesis 1:

1a. As compared to the control group, the intervention group will have decreased their perceptions of potential barriers as evident by the FAB survey at 6-weeks post intervention and follow-up. 
1b. As compared to the control group, the intervention group will have improved self-efficacy as evident by the FAB survey at 6-weeks post intervention and follow-up.

Specific Aim 2:

To determine if a nutrition and yoga intervention among breast cancer survivors will improve diet quality and physical activity.

Hypothesis 2:

2a. As compared to the control group, the intervention group will have improved dietary quality by increasing fruit and vegetable consumption and dietary knowledge as evident by the FAB Survey at 6-weeks post intervention and follow-up.

2b. As compared to the control group, the intervention group will increase their physical activity levels to meet, or exceed, the US Guidelines for Physical Activity as evident by the FAB Survey.

Specific Aim 3:

To determine if a nutrition and yoga intervention among breast cancer survivors will improve quality of life.

Hypothesis 3:

3a. As compared to the control group, the intervention group will improve quality of life as evident by decreasing perceived barriers to improve their health at 6-weeks post intervention and follow-up.

3b. As compared to the control group, the intervention group will improve quality of life as evident by improving self-efficacy at 6-weeks post intervention and follow-up. 
3c. As compared to the control group, the intervention group will improve quality of life as evident by improving diet quality at 6-weeks post intervention and follow-up.

3d. As compared to the control group, the intervention group will improve quality of life as evident by improving physical activity at 6-weeks post intervention and followup.

\section{Materials and Methods}

Subject Recruitment. This study was a randomized controlled trial with participants recruited by a convenience sample. Participants were recruited through multiple mechanisms, including social media marketing and flyer distribution at yoga studios, and community events. Social media marketing targeting individuals residing within a twenty-five-mile radius of American Yoga studio in Deerfield Beach, Florida and twenty-five miles of Yoga Journey in Boca Raton, Florida. The study consisted of a 6-week nutrition and yoga intervention and a follow-up visit six weeks post-intervention (week 12) to measure sustainability of the intervention.

Participants were directed to a study specific landing page to inquire about enrollment, https://tammyfogarty.lpages.co/nutrition-for-survivors/. Once an inquiry was submitted, individuals were contacted via telephone for initial screening. If they met preliminary eligibility criteria, an in-person screening was scheduled at American Yoga in Deerfield Beach, Florida where they signed the informed consent and completed the study questionnaires. Participants were also asked to perform simple movements (e.g., lifting arms overhead, moving from a standing position to seated position on floor, 
moving from seated to a standing position) to ensure safety for yoga practice. Eligible participants were enrolled in the study using random assignment into either the intervention or control group. The intervention group received nutrition education from a study specific website, Nutrition for Survivors, https://tammyfogarty.teachable.com/p/nutrition-for-survivors/. The website contained an in-depth explanation of the role of nutrition as it relates to breast cancer survivors and the prevention of cancer recurrence. The website contains short educational videos and the video material was transcribed and uploaded to the website for those that wanted to print the materials. Optional short quizzes were provided to test knowledge and a comment section was available for comments and feedback to improve study adherence. Education materials were presented on a weekly basis and subjects received notifications via e-mail and social media via a private Facebook page, throughout the duration of the study in an effort to maintain compliance. The website included six learning modules: Nutrition 101, Carbohydrates, Fats, Protein, Weight Management, and Antioxidants

Dietary recommendations for this study is consistent with the ACS recommendations for cancer prevention. Results from the EPIC study by Romaguera et al., (2012) suggests adherence to the WCRF/AICR recommendations for cancer prevention may lower the risk of most types of cancer. Cancer recurrence is of great importance to BCS therefore these recommendations, which are also consistent with the ACS guidelines, are appropriate for BCS. 
The intervention group received six weeks of Hatha yoga classes at American Yoga in Deerfield Beach, Florida. Numerous yoga classes were offered daily and participants were encouraged to attend at least two classes per week in order to meet US physical activity guidelines of 150 minutes per week. Subjects were asked to record any yoga activity outside of the yoga studio to be submitted at the end of the study. The yoga intervention was delivered as an instructor-taught, group format, for 75 minutes each time over a six-week period. The yoga classes included various yoga poses and breathing technique.

The control group received standardized education materials from the American Cancer Society Guidelines on Nutrition and Physical Activity for Cancer Prevention and a one-hour nutrition consultation from a Registered Dietitian at baseline. Participants in the control group were wait listed for yoga classes and access to the study website for nutrition information after completion of the study.

\section{$\underline{\text { Measurements }}$}

The Transactional Model of Stress and Coping, developed by Lazarus and Folman (1987), guided the selection of explanatory variables for quality of life. Modifications to the model reflect the hypothesis in that the introduction of a nutrition and yoga intervention will affect both the primary and secondary appraisals thus influencing quality of life (see figure 1). 
Figure 1. Transaction Model of Stress and Coping
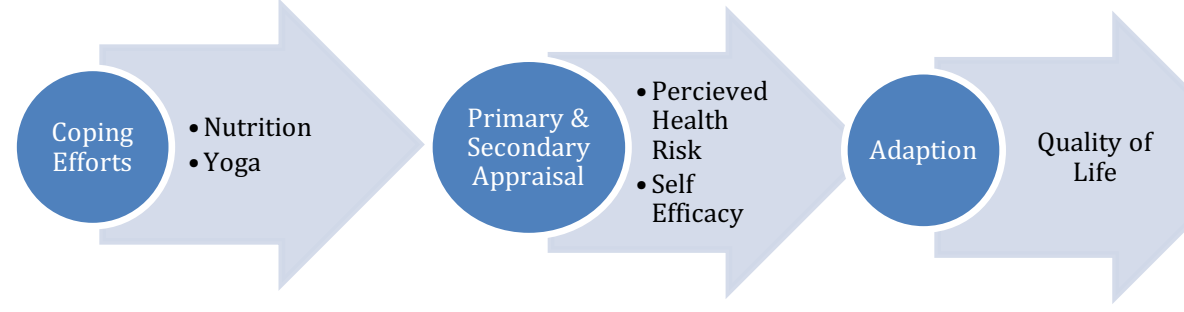

The primary and secondary appraisals were measured using the Food Attitude and Behavior (FAB) Survey. The FAB survey was developed by the National Cancer Institute (2013) to evaluate a variety of factors that may be related to fruit and vegetable consumption. Constructs of the survey includes self-efficacy, barriers, social support, knowledge of fruit and vegetable intake, views on vegetarianism, and environmental influences. The survey included 65 questions separated in eight sections related to attitudes and beliefs, shopping, general health, fruit and vegetable consumption, eating behaviors, physical activity, sedentary behaviors, and food preferences (National Cancer Institute, 2013). The following describes the constructs of the Food Attitudes and Behaviors Survey (FAB) that were utilized to measure perceived barriers (primary appraisal), self-efficacy (secondary appraisal), and coping efforts as outlined in the Stress and Coping model.

Psychosocial constructs on the FAB survey include self-efficacy and perceived barriers. These constructs have been shown to be strong correlates to the intake of fruit and vegetables (FV) and physical activity (PA) in previous studies (Erinosho et al., 2016, McSpadden et al., 2012). Self-efficacy measures confidence to consume FV and included 25 questions from the FAB survey. The options are based on a 5 point Likert scale with 1 
being "not true at all" and 5 being "very true". A higher score represents an increase in self-efficacy. Perceived barriers measures items that interfere with FV intake, such as access, cost, and shelf-life of food. Eleven questions from the FAB survey were included and are based on a 5 point Likert scale with 1 being "strongly disagree" and 5 being "strongly agree". A higher score represents increased perceived barriers while a lower score represents less perceived barriers.

Coping efforts were provided to participants through nutrition education to determine intake of FV and yoga classes to increase the frequency of physical activity. FV intake was measured by the frequency FV were consumed and the amount that was consumed each time FV were consumed. Three questions pertain to the frequency and asks "In the last month, how often did you eat X". Choices were on a scale of 1-10 with 1 being "Never" and 10 being " 5 or more times per day". A higher score represents an increase in FV consumption. The amount consumed included three questions from the FAB survey that asks "About how much did you have each time you ate X". Options were on a scale of $1-5$ with 1 being "did not eat $\mathrm{X}$ in the last month" and 5 being "more than 2 cups". A higher score indicates an increase in the amount of FV consumed.

Physical activity was measured by how often the participant engaged in exercise, including yoga, in a typical week. One question was chosen from the FAB survey and the choices were on a scale of 1-8 with 1 being "None" and 8 being "7 days per week". The higher the score reflects an increased frequency in physical activity per week. The constructs are outlined in Table 1. 
Table 1. Fifty questions obtained from FAB survey to define constructions, with Cronbach's Alpha

Cronbach's Alpha

\begin{tabular}{|c|c|c|c|c|}
\hline Construct & Items for measuring construct & Baseline & $\begin{array}{l}\text { Post- } \\
\text { Intervention }\end{array}$ & $\begin{array}{l}\text { Follow- } \\
\text { Up }\end{array}$ \\
\hline \multicolumn{5}{|l|}{ Perceived } \\
\hline \multirow{12}{*}{ barriers } & They cost too much & & & \\
\hline & They often spoil before I get a chance to eat them & & & \\
\hline & They take too much time to prepare & & & \\
\hline & They ae not filling enough & & & \\
\hline & My family doesn't like them & & & \\
\hline & The restaurants I go to don't serve fruit & & & \\
\hline & The restaurants I go to don't serve vegetables & & & \\
\hline & I have trouble digesting them & & & \\
\hline & I don't know how to choose fresh fruit and vegetables & & & \\
\hline & I just don't think of fruits and vegetables when I'm looking for something to eat & & & \\
\hline & They are too messy & & & \\
\hline & Thinking about yourself, if you were to eat plenty of fruits and vegetables & & & \\
\hline \multirow[t]{37}{*}{ Self-Efficacy } & every day, how likely would you be to: & 0.915 & 0.945 & 0.962 \\
\hline & Have more energy & & & \\
\hline & Live a long life & & & \\
\hline & Control your weight & & & \\
\hline & Look better (appearance) & & & \\
\hline & Be "regular" (have bowel movements) & & & \\
\hline & Feel good about yourself & & & \\
\hline & A Reason I eat fruits and vegetables is: & 0.921 & 0.921 & 0.944 \\
\hline & Because I want to feel in control of my health & & & \\
\hline & Because I want to set a good example for my family & & & \\
\hline & Because I have a strong value for eat healthy & & & \\
\hline & Because I personally believe it is a good thing for my health & & & \\
\hline & Because others would be upset with me if I did not & & & \\
\hline & Because I have carefully thought about it and believe it is very important for me & & & \\
\hline & Because I would feel better about myself if I did eat a healthy diet & & & \\
\hline & Because I would like to improve my physical health & & & \\
\hline & Because it is an important choice I really want to make & & & \\
\hline & Because I feel pressure from others to eat fruits and vegetables & & & \\
\hline & Because it is consistent with my life goals & & & \\
\hline & Because I want others to approve of me & & & \\
\hline & Because it is important for being as healthy as possible & & & \\
\hline & Because it is easier to do what I am told than to think about it & & & \\
\hline & Because I want others to see I can do it & & & \\
\hline & Because I want to take responsibilty for my own health & & & \\
\hline & Because I want to set a good example for my community & & & \\
\hline & Because it is important to treat my body with respect & & & \\
\hline & Because I don't want to let others down & & & \\
\hline & How confident are you that you could: & 0.932 & 0.955 & 0.959 \\
\hline & Eat a healthy snack, like a fruit or a vegetable, when you're really hungry? & & & \\
\hline & Eat healthy foods, like fruits or vegetables, when you are tired? & & & \\
\hline & Eat healthy foods, like fruits or vegetables, when there are junk foods in your & & & \\
\hline & house like chips, cookies, and candy? & & & \\
\hline & Eat fruit instead of cake, cookies, candy, ice cream, or other sweets for dessert? & & & \\
\hline & Eat fruits and vegetables when your family and friends are eating junk foods like & & & \\
\hline & chips, cookies, and candy? & & & \\
\hline & Buy or bring fruits and vegetables to eat at work? & & & \\
\hline & Snack on fruits and vegetables rather than on junk foods while watching TV? & & & \\
\hline \multicolumn{5}{|l|}{ Coping } \\
\hline Efforts- & & & & \\
\hline \multirow{8}{*}{ Nutrition } & What you ate in the last month: & 0.712 & 0.737 & 0.656 \\
\hline & During the last month, how often did you eat fruit? & & & \\
\hline & $\begin{array}{l}\text { During the last month, how often did you eat lettuce or a green, leafy salad, } \\
\text { with or without other vegetables }\end{array}$ & & & \\
\hline & $\begin{array}{l}\text { During the last month, how often did you eat other vegetables including string } \\
\text { beans, carrots, corn, tomatoes, collard greens, broccoli }\end{array}$ & & & \\
\hline & About how much did you eat each time you ate: & 0.723 & 0.743 & 0.49 \\
\hline & About how much did you have each time you ate fruit & & & \\
\hline & About how much did you have each time you ate salad & & & \\
\hline & About how much did you have each time you ate other vegetables & & & \\
\hline
\end{tabular}


Quality of life is the primary outcome of the study and is measured with the FACT-B + 4 Quality of Life Index. The FACT-B QoL index was developed by the Functional Assessment of Chronic Illness Therapy (FACIT) Measurement System and includes a collection of health-related QoL questionnaires to manage chronic illness. The Functional Assessment of Cancer Therapy-Breast (FACT-B) index was developed and validated for use in cancer patients and survivors (Webster, Cella, \& Yost, 2003). The survey measures four primary life domains: Physical Well-Being (PWB; 7 items), Social/Family Well-Being (SWB; 7 items), Emotional Well-Being (EWB; 6 items), and Functional Well-Being (FWB; 7 items), Additional Concerns includes a Breast Cancer Subscale (BCS; 10 items) plus an Arm Subscale (ARM; 5 items).

The Total Outcome Index (TOI) measures PWB + FWB + BCS with a total score range of 0-96. The FACT-G total score measures PWB + SWB + EWB + FWB with a total score range of 0-108. Finally, the FACT-B total score measures PWB $+\mathrm{SWB}+$ $\mathrm{EWB}+\mathrm{FWB}+\mathrm{BCS}$ with a total score range of 0-148. A higher score represents increased QoL. TOI endpoint is most commonly used in clinical trials because it is responsive to change in physical and functional outcomes. While emotional and social well-being are equally important, they are less likely to change over time as compared to physical and functional well-being (Webster, Cella, \& Yost, 2003).

The FACT-B +4 Quality of Life index and the Food Attitudes and Behaviors Survey. The assessments were administered at baseline, post-intervention (6 weeks) and 
again at the follow-up (12 weeks). All assessments completed at American Yoga and later data collected was entered electronically using RedCap software. Weight will be measured at American Yoga at base line, 6-weeks post intervention, and at follow-up.

Inclusion Criteria:

- Women diagnosed with stage I, II, or III cancer

- Women must be cancer free and post treatment for at least 6 months

- Women ages 30-60 years of age

- Must be willing and physically able to participate in at least two Hatha yoga classes weekly

- Must be free of any diagnosed illness(es) that will impact their ability to participate in the study

- Has not participated in regular physical activity ( $<150$ minutes), including yoga, within the past three months

- Must be able to tolerate and perform yoga in a slightly heated room (yoga room is not air conditioned however fans are available)

- Must be able to read in English

- Must have access a computer and internet

\section{Exclusion Criteria:}

- Males

- Older than 60 or younger than 30 years old 
- Pregnant

- Exercise on a regular basis ( $>150 \mathrm{~min} /$ week of moderate to vigorous physical activity)

- Medical condition limiting moderate physical activity

- Have existing cancer or receiving cancer treatments (Tamoxifin exluded)

- Medical conditions that may interfere with safe yoga practice

Methods and Procedures

Participants completed the following information at baseline:

- Informed consent signed

- Sociodemographic questionnaire

- Past Medical History questionnaire

- $\quad$ FACT-B +4 version 4

- Food Attitudes and Behaviors Survey

- Body Mass Index (BMI)

After six weeks and again at twelve weeks participants completed the following:

- $\quad$ FACT-B version 4

- Food Attitudes and Behaviors Survey

- $\mathrm{BMI}$ 


\section{$\underline{\text { Statistical Analysis }}$}

The IBM statistical package for the social sciences (SPSS) version 25 was used for performing statistical analysis. Descriptive statistics were conducted for baseline characteristics. There were no extreme outliers and the data was normally distributed, as assessed by boxplot and Shapiro-Wilk's test, respectively. Continuous data were compared using independent t-test while categorical data were compared using frequencies, independent and paired samples t-test, and Fisher's exact test, respectively. All data was measured at three different time points: baseline, post-intervention ( 6 weeks), and follow-up (12 weeks). Quality of life data were input as continuous and were analyzed using one-way repeated measures ANOVA, paired samples t-test, and post hoc analysis with Bonferroni adjustment. Internal consistency and reliability was assessed for each construct, and within each scale, of the FAB survey with Cronbach's alpha. Constructs of the FAB survey were categorical and analyzed with one-way repeated measures ANOVA, paired samples t-test, and post hoc analysis with Bonferroni adjustment. Testing Mediation with regression analysis were used to compare the intervention and control groups at the different time points on perceived barriers, selfefficacy, diet quality, physical activity, and quality of life measures. Mediation analysis demonstrated the relationship between the intervention (nutrition education and yoga) and QoL by affecting the primary and secondary appraisals derived from the Transactional Model of Stress and Coping.

To calculate the sample size for the difference between time points within each group, G*Power software was used with a medium effect size of 0.5 , alpha $0.05,80 \%$ 
power. The software indicated that a total sample size of 30 subjects was needed. Based on Bonferroni post hoc analysis, adjusted alpha of $0.016(0.05 / 3)$ with a medium effect of 0.5 , and $80 \%$ power a minimum of 39 subjects was required. Effect size was determined with alpha 0.016 and $80 \%$ power to achieve an effect size of 0.49 .

\section{$\underline{\text { Results }}$}

Fifty-two women were screened and 31 met inclusion criteria and were eligible to participate in the study. Twenty-seven women signed the informed consent and were randomly assigned into the intervention group $(n=14,51.9 \%)$ or the control group $(n=$ $13,48.1 \%)$. Three participants in the intervention group were excluded for missing values in the FAB Survey at baseline and one participant from the control group withdrew consent. One participant in the intervention and two from the control group were lost to follow-up. Twenty-four women completed the study. Fisher's exact test was conducted and determined observed frequencies and percentages for age, race, education, marital status, employment, and household income. P-values for Fisher's exact test determined the two groups were equally distributed. Observed frequencies, percentages, and $P$-value are presented in table 2. Weight was reported at baseline, post-intervention, and followup. Mean scores for the control group are $146.08 \pm 20.37,144.23 \pm 19.25$, and $142.15 \pm$ 18.09 and $147.69 \pm 20.34,145.08 \pm 18.79$, and $143.46 \pm 19.04$ for the intervention group. There were no significant differences in weight between the two groups or by group $\mathrm{x}$ time. 
Table 2. Crosstabulation of sociodemographic characteristics

\begin{tabular}{|c|c|c|c|}
\hline Variable & $\begin{array}{c}\text { Control, } \mathrm{n}(\% \text { within age group }) \\
\mathrm{n}=13(48.1 \%)\end{array}$ & $\begin{array}{l}\text { Intervention(\% within age group) } \\
\mathrm{n}=14(51.9 \%)\end{array}$ & $P$ value \\
\hline Age (years) & & & 0.838 \\
\hline $30-40$ & $1(50 \%)$ & $1(50 \%)$ & \\
\hline $41-50$ & $4(40 \%)$ & $6(60 \%)$ & \\
\hline $51-60$ & $8(53.3 \%)$ & $7(46.7 \%)$ & \\
\hline Race & & & 0.259 \\
\hline Caucasian & $8(40 \%)$ & $12(60 \%)$ & \\
\hline Hispanic/Latino & $4(66.7 \%)$ & $2(33.3 \%$ & \\
\hline African American & $1(100 \%)$ & $0(0 \%)$ & \\
\hline Education (degree) & & & 0.058 \\
\hline High School or less & $2(100 \%)$ & $0(0 \%)$ & \\
\hline Associate & $2(100 \%)$ & $0(0 \%)$ & \\
\hline Bachleor & $5(33.3 \%)$ & $10(66.7 \%)$ & \\
\hline Master & $4(66.7 \%)$ & $2(33.3 \%)$ & \\
\hline Professional & $0(0 \%)$ & $2(100 \%)$ & \\
\hline Marrital Status & & & 0.297 \\
\hline Single & $0(0 \%)$ & $3(100 \%$ & \\
\hline Married/Partnered & $10(52.6 \%)$ & $9(47.4 \%)$ & \\
\hline Divorced & $2(50 \%)$ & $2(50 \%)$ & \\
\hline Widowed & $1(100 \%)$ & $0(0 \%)$ & \\
\hline Employment & & & 1.00 \\
\hline Employed & $10(47.6 \%)$ & $11(52.4 \%)$ & \\
\hline Self-employed & $1(33.3 \%)$ & $2(66.7 \%)$ & \\
\hline Unemployed & $1(50 \%)$ & $1(50 \%)$ & \\
\hline Retired & $1(100 \%)$ & $0(0 \%)$ & \\
\hline Household Income (\$) & & & 0.366 \\
\hline $50,000-74,999$ & $1(25 \%)$ & $3(75 \%)$ & \\
\hline $75,000-99,999$ & $4(80 \%)$ & $1(20 \%)$ & \\
\hline $100,000-149,999$ & $3(50 \%)$ & $3(50 \%)$ & \\
\hline 150,000 or higher & $1(20 \%)$ & $4(80 \%)$ & \\
\hline Prefer not to disclose & $4(57.1 \%)$ & $3(42.9 \%)$ & \\
\hline
\end{tabular}

Mean Total Outcome Index (TOI) at baseline, post-intervention, and follow-up for the control group were $66.90 \pm 11.51,68.20 \pm 12.91$, and $69.60 \pm 13.39$ and mean scores for the intervention group were $59.85 \pm 17.12,69.85 \pm 11.75,70.31 \pm 13.60$. There were no significant findings in mean scores between the intervention and control group. A one-way repeated measures ANOVA was conducted to determine whether there was a statistically significant difference in TOI QoL scores for the duration of the study. The intervention elicited statistically significant differences over time within groups, $F$ 
$(2,42)=5.852, p<.05$, partial $\eta^{2}=.218$ however the intervention did not reveal a statistically significant result between the two groups, $\mathrm{F}(1)=41.619, p=.081$, partial $\eta^{2}$ $=.004$. Post hoc analysis with Bonferroni adjustment found a statistically significant difference from baseline to post-intervention, -10.000 (95\% CI -16.151 to -3.849$) p<$ .005 , and from baseline to follow-up baseline to follow-up, -10.462 (95\% CI -16.939 to $3.984), p<.005$, in the intervention group. There were no significant findings in the control group between time points.

Mean FACT-G QoL scores for the control group at baseline, post-intervention, and follow-up were $77.80 \pm 14.97,80.20 \pm 15.48$, and $80.10 \pm 15.74$ and $75.08 \pm 18.21$, $87.23 \pm 12.34$, and $85.62 \pm 13.26$ for the intervention group. There were no significant differences in mean score between the control and intervention group. The one-way repeated measures ANOVA analysis determined statistically significant changes over time, $F(2,42)=715.157, p<.005$, partial $\eta^{2}=.352$, as well as within the groups, $F(2,42)=4.948, p<.05$, partial $\eta^{2}=.191$ however there were no significant findings between the two groups, $\mathrm{F}(1)=.294, p=.594$, partial $\eta^{2}=.014$. Post hoc analysis with Bonferroni adjustment revealed a statistically significant difference from baseline to postintervention, $-12.154(95 \% \mathrm{CI}-19.660$ to -4.648$), p<.005$, and from baseline to followup, $-10.538(95 \%$ CI -18.707 to -2.370$), p<.05$, for the intervention group and there were no significant findings between time points for the control group. 
The mean FACT-B QoL scores for the control group at baseline, postintervention, and follow-up were 101.30 $\pm 19.88,104.60 \pm 21.11$, and $105.40 \pm 21.48$ and $95.77 \pm 25.88,110.23 \pm 18.08$, and $109.77 \pm 20.52$ for the intervention group. A one-way repeated measures ANOVA found statistically significant differences for time, $F(2,42)=$ $10.952, p<.005$, partial $\eta^{2}=.343$, and within groups, $F(2,42)=3.817, p<.05$, partial $\eta^{2}$ $=.154$. A post hoc analysis with Bonferroni adjustment revealed a statistically significant difference between baseline and post-intervention, -14.462 (95\% CI, -23.564 to -5.359), $p$ $<.005$ and between baseline and follow-up, -14.462 (95\% CI, -23.564 to -5.359$), p<.005$, in the intervention group. There were no significant differences between time points for the control group.

Table 3. Mean scores for quality of life for Total Outcome Index, FACT-G, and FACT-B

\begin{tabular}{|c|c|c|c|}
\hline \multirow[b]{2}{*}{ Variable } & Control & Intervention Mean & \multirow{2}{*}{$P$-value } \\
\hline & SD & $\pm \mathrm{SD}$ & \\
\hline \multicolumn{4}{|c|}{ Total Outcome Index } \\
\hline Baseline & $66.90 \pm 11.51$ & $59.85 \pm 17.12$ & 0.258 \\
\hline Post-Intervention & $68.20 \pm 12.91$ & $69.85 \pm 11.75$ & 0.752 \\
\hline Follow-up & $69.60 \pm 13.39$ & $70.31 \pm 13.60$ & 0.902 \\
\hline \multicolumn{4}{|l|}{ FACT-G } \\
\hline Baseline & $77.80 \pm 14.97$ & $75.08 \pm 18.21$ & 0.781 \\
\hline Post-Intervention & $80.20 \pm 15.48$ & $87.23 \pm 12.34$ & 0.208 \\
\hline Follow-up & $80.10 \pm 15.74$ & $85.62 \pm 13.26$ & 0.372 \\
\hline \multicolumn{4}{|l|}{ FACT-B } \\
\hline Baseline & $101.30 \pm 19.88$ & $95.77 \pm 25.88$ & 0.642 \\
\hline Post-Intervention & $104.60 \pm 21.11$ & $110.23 \pm 18.08$ & 0.472 \\
\hline Follow-up & $105.40 \pm 21.48$ & $109.77 \pm 20.52$ & 0.625 \\
\hline
\end{tabular}


Mean scores for perceived barriers were analyzed, with a lower score indicated fewer perceived barriers. The baseline, post-intervention, and follow-up data for the control group are $22.23 \pm 9.23,19.83 \pm 8.66$, and $21.54 \pm 10.47$ and $22.08 \pm 7.23,20.33$ \pm 5.35 , and $17 \pm 5.49$ for the intervention group. There were no significant differences in mean scores between the control and intervention group. One-Way Repeated Measures ANOVA was conducted to determine whether there was a statistically significant difference in perceived barriers at baseline, post intervention, and follow-up. The results did not show any significant findings for time, $F(2,40)=2.536, p=.092, \eta^{2}=.113$, or within groups, $F(2,40)=1.841, p=.172, \eta^{2}=.084$. Similar findings were observed for self-efficacy. Mean scores, with higher values reflecting improved self-efficacy, at baseline, post-intervention, and follow-up for the control group are: $114.85 \pm 23.53$, $123.17 \pm 24.11$, and $121.82 \pm 28.47$ and $110.46 \pm 16.62,124.58 \pm 14.64$, and $120.45 \pm$ 23.32 for the intervention group. There were no significant differences between the intervention and control groups, $F(1.24,23.557)=.730, p=.430$, partial $\eta^{2}=.037$ however there was a marginal difference in time, $F(1.24,23.557)=3.847, p=$., partial $\eta^{2}$ $=.168$. However, paired samples t-test did reveal a significant difference between baseline and post-intervention for the intervention group, $t(11)=-2.813, p=.017$. There were no significant findings in the intervention group for baseline to follow-up and no significant differences in the control group between any time points.

Diet quality was measured using the FAB survey and was reported as how often fruits and vegetables were consumed and how much was consumed each time. Tables 4 , 
5 , and 6 represent the frequency and percentage of fruits and vegetables consumed. Oneway repeated measures ANOVA indicated a statistically significant finding between time, $F(2,40)=.3 .957, p<0.05$, partial $\eta^{2}=.165$, however there was no significant findings between the control and intervention groups for how often fruits and vegetables were consumed, $F(2,40)=.620, p=.538$.

Table 4. Frequency and percent distribution for "During the past month, how often did you eat fruit?"

\begin{tabular}{l|cc|cc}
\multicolumn{2}{c}{ Control Group (N = 13) } & \multicolumn{2}{c}{ Intervention (N = 13) } \\
\hline Variable & Frequency & Percent & Frequency & Percent \\
\hline Baseline & & & & \\
1-2 times per week & 3 & 23.1 & 1 & 7.7 \\
3-4 times per week & 4 & 30.8 & 2 & 15.4 \\
5-6 times per week & 3 & 23.1 & 2 & 15.4 \\
1 time per day & 1 & 7.7 & 2 & 15.4 \\
2 times per day & 1 & 7.7 & 4 & 30.8 \\
3 times per day & 1 & 7.7 & 2 & 15.4 \\
Post-Intervention & & & & \\
1-2 times per week & 3 & 25.0 & 1 & 8.3 \\
3-4 times per week & 3 & 25.0 & 4 & 33.3 \\
5-6 times per week & 2 & 16.7 & 1 & 8.3 \\
1 time per day & 1 & 8.3 & 2 & 16.7 \\
2 times per day & 1 & 8.3 & 1 & 8.3 \\
3 times per day & 1 & 8.3 & 3 & 25.0 \\
4 times per day & 1 & 8.3 & - & - \\
Follow-Up & & & & \\
1-3 times last month & - & - & 1 & 8.3 \\
1-2 times per week & 4 & 36.4 & 1 & 8.3 \\
3-4 times per week & 2 & 18.2 & 1 & 8.3 \\
5-6 times per week & 2 & 18.2 & 1 & 8.3 \\
1 time per day & 1 & 9.1 & 2 & 16.7 \\
2 times per day & 2 & 18.2 & 4 & 33.3 \\
3 times per day & - & - & 1 & 8.3 \\
4 times per day & - & - & 1 & 8.3 \\
\hline
\end{tabular}


Table 5. Frequency and percent distribution for "During the past month, how often did you eat lettuce or green, leafy salad, with or without other vegetabes?"

\begin{tabular}{l|cc|cc}
\hline & \multicolumn{2}{c}{ Control Group $(\mathrm{N}=13)$} & \multicolumn{2}{c}{ Intervention $(\mathrm{N}=13)$} \\
\hline Variable & Frequency & Percent & Frequency & Percent \\
\hline Baseline & & & & \\
1-3 times last month & - & - & 1 & 7.7 \\
1-2 times per week & 7 & 53.8 & 5 & 38.5 \\
3-4 times per week & 3 & 23.1 & 2 & 15.4 \\
5-6 times per week & 2 & 15.4 & 2 & 15.4 \\
1 time per day & 1 & 7.7 & 1 & 7.7 \\
2 times per day & - & - & 2 & 15.4 \\
Post-Intervention & & & & \\
1-2 times per week & 4 & 33.3 & 1 & 8.3 \\
3-4 times per week & 3 & 25.0 & 4 & 33.3 \\
5-6 times per week & 3 & 25.0 & 2 & 16.7 \\
1 time per day & 1 & 8.3 & 2 & 16.7 \\
2 times per day & 1 & 8.3 & 3 & 25.0 \\
Follow-Up & & & & \\
1-2 times per week & 4 & 36.4 & 2 & 16.7 \\
3-4 times per week & 3 & 27.3 & 4 & 33.3 \\
5-6 times per week & 2 & 18.2 & 1 & 8.3 \\
1 time per day & 2 & 18.2 & 2 & 16.7 \\
2 times per day & - & - & 3 & 25.0 \\
\hline
\end{tabular}


Table 6. Frequency and percent distribution for "During the past month, how oftendid you eat other vegetables? Such as string beans, carrots, corn, peas, tomatoes, collard greens, and broccoli"

\begin{tabular}{|c|c|c|c|c|}
\hline & \multicolumn{2}{|c|}{ Control Group $(\mathrm{N}=13)$} & \multicolumn{2}{|c|}{ Intervention $(\mathrm{N}=13)$} \\
\hline Variable & Frequency & Percent & Frequency & Percent \\
\hline \multicolumn{5}{|l|}{ Baseline } \\
\hline 1-3 times last month & 1 & 7.7 & 1 & 7.7 \\
\hline 1-2 times per week & 4 & 30.8 & 4 & 30.8 \\
\hline 3-4 times per week & 3 & 23.1 & 4 & 30.8 \\
\hline 5-6 times per week & 3 & 23.1 & 2 & 15.4 \\
\hline 1 time per day & 1 & 7.7 & - & - \\
\hline 2 times per day & - & - & 1 & 7.7 \\
\hline 3 times per day & 1 & 7.7 & 1 & 7.7 \\
\hline \multicolumn{5}{|l|}{ Post-Intervention } \\
\hline 1-3 times last month & 1 & 8.3 & - & - \\
\hline 1-2 times per week & 2 & 16.7 & 1 & 8.3 \\
\hline 3-4 times per week & 3 & 25.0 & 4 & 33.3 \\
\hline 5-6 times per week & 3 & 25.0 & 2 & 16.7 \\
\hline 1 time per day & 2 & 16.7 & 2 & 16.7 \\
\hline 2 times per day & 1 & 8.3 & 2 & 16.7 \\
\hline 3 times per day & - & - & 1 & 8.3 \\
\hline \multicolumn{5}{|l|}{ Follow-Up } \\
\hline 1-3 times last month & 1 & 7.7 & - & - \\
\hline 1-2 times per week & 1 & 7.7 & 2 & 16.7 \\
\hline 3-4 times per week & 5 & 38.5 & 5 & 41.7 \\
\hline 5-6 times per week & 2 & 15.4 & 2 & 16.7 \\
\hline 1 time per day & 1 & 7.7 & 2 & 16.7 \\
\hline 2 times per day & 1 & 7.7 & 1 & 8.3 \\
\hline
\end{tabular}

Tables 7, 8, and 9 represent the frequency and percentage of the amount of fruits and vegetables consumed each time that food item was eaten. There was no significant findings over time, $F(1.450,29.002)=.964, p=.390$, partial $\eta^{2}=.046$, or between the two groups, $F(1.450,29.002)=1.627, p=.216$, partial $\eta^{2}=.075$. There was a statistically significant difference in the intervention group for differences between 
baseline and post-intervention $t(11)=-2.303, p<.05$, however there were no significant differences between baseline and follow-up, $\mathrm{t}(10)=2.055, p=.067$.

Table 7. Frequency and percent distribution for "About how much did you have each time you ate vegetables?"

\begin{tabular}{|c|c|c|c|c|}
\hline & \multicolumn{2}{|c|}{ Control Group $(\mathrm{N}=13)$} & \multicolumn{2}{|c|}{ Intervention $(\mathrm{N}=13)$} \\
\hline Variable & Frequency & Percent & Frequency & Percent \\
\hline Baseline & & & & \\
\hline $1 / 2$ to 1 cup & 9 & 69.2 & 6 & 46.2 \\
\hline 1 to 2 cups & 4 & 30.8 & 7 & 53.8 \\
\hline Post-Intervention & & & & \\
\hline $1 / 2$ to 1 cup & 8 & 66.7 & 3 & 25.0 \\
\hline 1 to 2 cups & 4 & 33.3 & 8 & 66.7 \\
\hline more than 2 cups & - & - & 1 & 8.3 \\
\hline Follow-Up & & & & \\
\hline less than $1 / 2$ cup & - & - & 1 & 8.3 \\
\hline $1 / 2$ to 1 cup & 7 & 63.6 & 3 & 25.0 \\
\hline 1 to 2 cups & 4 & 100.0 & 8 & 66.7 \\
\hline
\end{tabular}

Table 8. Frequency and percent distribution for "About how much did you have each time you ate fruit?"

\begin{tabular}{|c|c|c|c|c|}
\hline & \multicolumn{2}{|c|}{ Control Group $(\mathrm{N}=13)$} & \multicolumn{2}{|c|}{ Intervention $(\mathrm{N}=13)$} \\
\hline Variable & Frequency & Percent & Frequency & Percent \\
\hline \multicolumn{5}{|l|}{ Baseline } \\
\hline less than $1 / 2$ cup or less than 1 medium fruit & 2 & 15.4 & 1 & 7.7 \\
\hline About $1 / 2$ cup or 1 medium fruit & 7 & 53.8 & 5 & 38.5 \\
\hline About 1 cup or 1 large fruit & 4 & 30.8 & 5 & 38.5 \\
\hline more than 1 cup or more than 1 large fruit & - & - & 2 & 15.4 \\
\hline \multicolumn{5}{|l|}{ Post-Intervention } \\
\hline less than $1 / 2$ cup or less than 1 medium fruit & 3 & 25.0 & - & - \\
\hline About $1 / 2$ cup or 1 medium fruit & 5 & 41.7 & 1 & 8.3 \\
\hline About 1 cup or 1 large fruit & 4 & 33.3 & 9 & 75.0 \\
\hline more than 1 cup or more than 1 large fruit & & & 2 & 16.7 \\
\hline \multicolumn{5}{|l|}{ Follow-Up } \\
\hline less than $1 / 2$ cup or less than 1 medium fruit & 2 & 18.2 & 1 & 8.3 \\
\hline About $1 / 2$ cup or 1 medium fruit & 5 & 45.5 & 3 & 25.0 \\
\hline About 1 cup or 1 large fruit & 4 & 36.4 & 6 & 50.0 \\
\hline more than 1 cup or more than 1 large fruit & - & - & 2 & 16.7 \\
\hline
\end{tabular}


Table 9. Frequency and percenet distribution for "About how much did you have each time you ate salad?"

\begin{tabular}{|c|c|c|c|c|}
\hline & \multicolumn{2}{|c|}{ Control Group $(\mathrm{N}=13)$} & \multicolumn{2}{|c|}{ Intervention $(\mathrm{N}=13)$} \\
\hline Variable & Frequency & Percent & Frequency & Percent \\
\hline Baseline & & & & \\
\hline about $1 / 2$ cup & 1 & 7.7 & - & - \\
\hline about 1 cup & 7 & 53.8 & 6 & 46.2 \\
\hline about 2 cups & 5 & 38.5 & 5 & 38.5 \\
\hline more than 2 cups & - & - & 2 & 15.4 \\
\hline Post-Intervention & & & & \\
\hline about $1 / 2$ cup & 1 & 8.3 & - & - \\
\hline about 1 cup & 6 & 50.0 & 2 & 16.7 \\
\hline about 2 cups & 5 & 41.7 & 8 & 66.7 \\
\hline more than 2 cups & - & - & 2 & 16.7 \\
\hline Follow-Up & & & & \\
\hline about $1 / 2$ cup & 1 & 9.1 & 1 & 8.3 \\
\hline about 1 cup & 5 & 45.5 & 2 & 16.7 \\
\hline about 2 cups & 5 & 45.5 & 6 & 50.0 \\
\hline more than 2 cups & - & - & 3 & 25.0 \\
\hline
\end{tabular}

Physical activity and exercise of at least moderate intensity was recorded as frequency (times per week) and duration (minutes each occurrence). Tables 10 and 11 represent the frequency and percentage of how often and how much time was spent conducting physical activity or exercise. A one-way repeated measure ANOVA was conducted to determine whether there was a statistically significant difference in frequency of physical activity over the duration of the study. The one-way repeated measures ANOVA showed that physical activity was statistically significant between time points, $F(2,40)=9.740, p<.005$, partial $\eta^{2}=.328$, however there was no difference between the groups, $F(2,40)=1.986, p=.166$, partial $\eta^{2}=.090$. Paired samples T-Test found a statistically significant difference between scores in the intervention group for 
baseline to post-intervention, $t(11)=-5.197, p<.05$. There were no significant findings from baseline to follow-up, $t(10)=1.936, p=.082$. Post hoc analysis with Bonferroni adjustment did not yield significant findings for the control group across any time point.

Table 10. Frequency and percent distribution for "In a typical week, how many days do you do any physical activity or exercise of at least moderate intensity?"

\begin{tabular}{|c|c|c|c|c|}
\hline & \multicolumn{2}{|c|}{ Control Group $(\mathrm{N}=13)$} & \multicolumn{2}{|c|}{ Intervention $(\mathrm{N}=13)$} \\
\hline Variable & Frequency & Percent & Frequency & Percent \\
\hline \multicolumn{5}{|l|}{ Baseline } \\
\hline None & 6 & 46.2 & 3 & - \\
\hline 1 day per week & 1 & 7.7 & 2 & 7.7 \\
\hline 2 days per week & - & - & 4 & 15.4 \\
\hline 3 days per week & 4 & 30.8 & 2 & 15.4 \\
\hline 4 days per week & 1 & 7.7 & 2 & 15.4 \\
\hline 5 days per week & - & - & - & - \\
\hline 7 days per week & 1 & 7.7 & - & - \\
\hline \multicolumn{5}{|l|}{ Post-Intervention } \\
\hline none & 4 & 33.3 & - & - \\
\hline 2 days per week & 1 & 8.3 & 1 & 8.3 \\
\hline 3 days per week & 4 & 33.3 & 6 & 50.0 \\
\hline 4 days per week & 1 & 8.3 & 3 & 25.0 \\
\hline 5 days per week & 1 & 8.3 & 2 & 16.7 \\
\hline 7 days per week & 1 & 8.3 & - & - \\
\hline \multicolumn{5}{|l|}{ Follow-Up } \\
\hline None & 4 & 36.4 & - & - \\
\hline 1 day per week & - & - & 1 & 8.3 \\
\hline 2 days per week & 1 & 9.1 & 4 & 33.3 \\
\hline 3 days per week & 2 & 18.2 & 3 & 25.0 \\
\hline 4 days per week & 3 & 27.3 & 2 & 16.7 \\
\hline 5 days per week & 1 & 9.1 & 2 & 16.7 \\
\hline
\end{tabular}


Table 11. Frequency and percent distribution for "On the days you do any physical activity or exercise, how long are you typically doing these activities?"

\begin{tabular}{|c|c|c|c|c|}
\hline & \multicolumn{2}{|c|}{ Control Group $(\mathrm{N}=13)$} & \multicolumn{2}{|c|}{ Intervention $(\mathrm{N}=13)$} \\
\hline Variable & Frequency & Percent & Frequency & Percent \\
\hline Baseline & & & & \\
\hline 0 minutes & 6 & 46.2 & 3 & 23.1 \\
\hline 20 minutes & 1 & 7.7 & - & - \\
\hline 30 minutes & 1 & 7.7 & 1 & 7.7 \\
\hline 45 minutes & 1 & 7.7 & - & - \\
\hline 60 minutes & 4 & 7.7 & 8 & 61.5 \\
\hline 90 minutes & - & - & 1 & 7.7 \\
\hline Post-Intervent & & & & \\
\hline 0 minutes & 5 & 38.5 & 1 & 7.7 \\
\hline 15 minutes & 1 & 7.7 & - & - \\
\hline 30 minutes & 1 & 7.7 & - & - \\
\hline 50 minutes & 1 & 7.7 & - & - \\
\hline 60 minutes & 3 & 23.1 & 7 & 53.8 \\
\hline 75 minutes & 1 & 7.7 & 3 & 23.1 \\
\hline 90 minutes & - & - & 2 & 15.4 \\
\hline 180 minutes & 1 & 7.7 & - & - \\
\hline Follow-Up & & & - & - \\
\hline 0 minutes & 5 & 38.5 & 1 & 7.7 \\
\hline 20 minutes & 1 & 7.7 & - & - \\
\hline 30 minutes & 2 & 15.4 & 1 & 7.7 \\
\hline 45 minutes & - & - & 1 & 7.7 \\
\hline 60 minutes & 2 & 15.4 & 4 & 30.8 \\
\hline 75 minutes & 1 & 7.7 & 3 & 23.1 \\
\hline 80 minutes & 1 & 7.7 & - & - \\
\hline 90 minutes & - & - & 3 & 23.1 \\
\hline 180 minutes & 1 & 7.7 & - & - \\
\hline
\end{tabular}

Mediation analysis with linear regression was conducted to demonstrate which mediating factor caused a relationship between the intervention (nutrition education and yoga) and QoL. The dependent variable for mediation analysis was TOI scores from the FACT-B questionnaire that was completed post-intervention (6 weeks). The mediators 
analyzed include perceived barriers (primary appraisal), self-efficacy (secondary appraisal), as well as frequency and amount of fruits and vegetables consumed, and physical activity. The outcome of mediation analysis can be seen in table 12 . The results of our analysis indicate the group has a direct effect on the amount of FV consumed (path A), $F(1,22)=15.053, p<.005, \mathrm{R}^{2}=.406$ and the group has a direct effect on perceived barriers, (path A), $F(1,20)=6.313, p=.021, \mathrm{R}^{2}=.240$. Mediation analysis for selfefficacy, frequency of FV consumption, and physical activity did not result in significant findings. Table 12 provides the mediation with regression analysis for all variables.

\begin{tabular}{|c|c|c|c|c|c|c|}
\hline Variable & Testing Path & $B$ & $S E B$ & $\beta$ & $t$ & $p$ \\
\hline $\mathrm{DV}=\mathrm{TOI}, \mathrm{IV}=$ Group & Path $\mathrm{C}, \mathrm{x} \rightarrow \mathrm{y}$ & 2.415 & 5.060 & 0.104 & 0.478 & 0.638 \\
\hline DV $=$ Percieved Barrior, $\mathrm{IV}=$ Group & Path $A, x \rightarrow m$ & 0.500 & 2.94 & 0.036 & 0.170 & 0.866 \\
\hline \multirow[t]{2}{*}{ DV $=$ TOI, IV $=$ Percieved Barriers $(b)+$ Group $\left(c^{\prime}\right)$} & Path $B, m \rightarrow y$ & -0.802 & 0.321 & -0.493 & -2.500 & 0.021 \\
\hline & Path $C^{\prime}, x \rightarrow y$ & 3.401 & 4.631 & 0.145 & 0.734 & 0.472 \\
\hline $\mathrm{DV}=\mathrm{TOI}, \mathrm{IV}=\mathrm{Group}$ & Path $C, x \rightarrow y$ & 2.415 & 5.060 & 0.104 & 0.478 & 0.638 \\
\hline DV $=$ Self Efficacy, $\mathrm{IV}=$ Group & Path $A, x \rightarrow m$ & 1.417 & 8.143 & 0.037 & 0.174 & 0.863 \\
\hline \multirow[t]{2}{*}{ DV $=$ TOI, IV $=$ Self Efficacy $(b)+$ Group $\left(c^{\prime}\right)$} & Path $B, m \rightarrow y$ & 0.018 & 0.134 & 0.303 & 0.132 & 0.896 \\
\hline & Path $C^{\prime}, x \rightarrow y$ & 3.116 & 5.336 & 0.133 & 0.584 & 0.566 \\
\hline $\mathrm{DV}=\mathrm{TOI}, \mathrm{IV}=\mathrm{Group}$ & Path $C, x \rightarrow y$ & 2.415 & 5.060 & 0.104 & 0.478 & 0.638 \\
\hline DV $=$ What Consumed, $\mathrm{IV}=$ Group & Path $A, x \rightarrow m$ & 2.083 & 1.579 & 0.271 & 1.320 & 0.200 \\
\hline \multirow[t]{2}{*}{ DV $=$ TOI, IV $=$ Self What Consumed (b) + Group (} & Path $B, m \rightarrow y$ & 0.827 & 0.696 & 0.274 & 1.188 & 0.249 \\
\hline & Path $C^{\prime}, x \rightarrow y$ & 1.148 & 5.414 & 0.049 & 0.212 & 0.834 \\
\hline $\mathrm{DV}=\mathrm{TOI}, \mathrm{IV}=$ Group & Path $C, x \rightarrow y$ & 2.415 & 5.060 & 0.104 & 0.478 & 0.638 \\
\hline DV $=$ Amount Consumed, $\mathrm{IV}=$ Group & Path $A, x \rightarrow m$ & 2.167 & 0.558 & 0.637 & 3.88 & 0.001 \\
\hline \multirow[t]{2}{*}{$\mathrm{DV}=\mathrm{TOI}, \mathrm{IV}=$ Self What Consumed $(\mathrm{b})+$ Group (} & Path $B, m \rightarrow y$ & 3.420 & 2.022 & 0.483 & 1.691 & 0.107 \\
\hline & Path $C^{\prime}, x \rightarrow y$ & -4.449 & 6.698 & -0.19 & -0.664 & 0.515 \\
\hline $\mathrm{DV}=\mathrm{TOI}, \mathrm{IV}=$ Group & Path $C, x \rightarrow y$ & 2.415 & 5.060 & 0.104 & 0.478 & 0.638 \\
\hline DV = Physical Activity, IV = Group & Path $A, x \rightarrow m$ & 1.250 & 0.724 & 0.345 & 1.726 & 0.098 \\
\hline \multirow[t]{2}{*}{ DV $=$ TOI, IV = Physical Activity (b) + Group $\left(c^{\prime}\right)$} & Path $B, m \rightarrow y$ & 2.297 & 1.437 & 0.37 & 1.599 & 0.126 \\
\hline & Path $C^{\prime}, x \rightarrow y$ & -0.197 & 5.427 & -0.008 & -0.036 & 0.971 \\
\hline
\end{tabular}




\section{$\underline{\text { Discussion }}$}

Results of this randomized, controlled trial indicate that a nutrition and yoga intervention may improve quality of life in BCS. Participants in the intervention group showed significant improvements in quality of life, diet quality, and physical activity from baseline to post-intervention and from baseline to follow-up, whereas participants in the control group did not show significant changes in outcomes.

Adherence to the nutrition and yoga intervention was excellent, with only three participants lost to follow-up throughout the duration of the study (one from the intervention and two from the control groups). This may be attributed to careful selection of yoga poses to be performed for individuals that were new to yoga or experience range of motion limitations. The online nutrition education was easily accessible and participants could view the materials from home at their convenience via video presentation and written communication to accommodate different learning styles. The control group received a nutrition consultation and a copy of the dietary guidelines from the American Cancer Society.

Yoga is used for a variety of conditions, including stress, anxiety, depression, and fatigue, as well as a method to increase physical activity in BCS (Sudarshan, 2013). A study conducted by Bower et al., (2012) conducted a 12-week yoga intervention with 3month follow-up in BCS with persistent fatigue. They found significant changes in 
fatigue severity by time $(P<.05)$, as well as significant improvements in vigor by time $(P$ $<.05)$ as compared to the control group that did not report any significant findings through the duration of the study. Both fatigue and vigor are factors related to QoL. Another study conducted by Cramer et al., (2015) also provided a 12-week yoga intervention with 3-month follow-up for BCS to decrease menopausal symptoms. The study showed consistent improvements by time for QoL $(P<.05)$ using the FACT-B questionnaire as compared to the control group that did not report significant changes. Both studies reported sustained improvements in outcomes as compared to our study that showed significant improvements from baseline to post-intervention and baseline to follow-up $(P<.005)$, but not from post-intervention to follow-up for Total Outcome Index (TOI) QoL scores. This could be due to the shorter duration of our study and a smaller sample size to detect significant differences between the control and intervention group for QoL.

An inclusion criterion for the current study was participants must be free of cancer and post- treatment for at least six months; there was no limitation as to how long they were post-treatment. Our study did not assess the differences in duration of posttreatment or the severity of late-effect side effects amongst the groups. A study conducted by Siedentopf et al., (2013) conducted a yoga intervention in women diagnosed with early breast cancer to assess yoga's impact on QoL. The study results found that yoga made more of an impact in women that started yoga immediately post-surgery as compared to women that were wait listed to receive yoga five-weeks post-surgery. The study found that overall QoL $(P<.005)$ and functional status $(P<.005)$ increased 
significantly in the intervention group receiving yoga immediately following surgery as compared to the control group. The same notion may hold true in BCS that those engaged in yoga immediately post-treatment may experience improved QoL as compared to women that wait years before engaging in yoga. Future studies should control for duration of time post-treatment to determine if early onset of physical activity has a great impact on QoL.

The World Cancer Research Fund / American Institute for Cancer Research (WCFR / AICR) has indicated there is limited evidence for specific dietary recommendations for BCS therefore they have advised that BCS should follow recommendations for cancer prevention. The American Cancer Society has provided guidelines on body weight, physical activity, and diet for cancer prevention, similar to those of WCFR / AICR recommendations. A study conducted by Song et al., (2015) found that increasing adherence to ACR guidelines was associated with higher scores of social functioning, $(P<.05)$. A comparable study conducted by Lei et al., (2018) assessed adherence to the WCRF / AICR recommendations is associated with quality of life in Chinese women with breast cancer. The study found that increasing adherence to the WCRF / AICR guidelines was associated with higher scores of global health status / quality of life $(P<.05)$. The findings of these two studies are comparable to our nutrition intervention and findings. The current study followed ACS and WCFR / AICR guidelines with an emphasis on increased consumption of fruit and vegetables and we saw a significant difference by time (baseline to post-intervention) for the frequency $(P<.05)$ and amount $(P<.05)$ of fruits and vegetables consumed however we did not see a 
significant difference between the intervention and control groups for frequency $(P=$ $.538)$ or amount consumed $(P=.216)$. Small sample size in the current intervention may have led to insignificant findings between the two groups. A larger sample size is suggested to determine differences between the two groups.

For outcomes related to physical activity there is evidence that engaging in physical activity improved quality of life. A meta-analysis of twenty-five exercise interventions to assess QoL in BCS reported an overall increase in QoL in the intervention group as compared to the control group (Zeng et al., 2014). Short-term exercise and nutrition interventions in BCS reported improvements in QoL with exercise and dietary intervention (Travier et al., 2014 \& Lee et al., 2014). The current study did show a significant difference from baseline to post-intervention $(P<.005)$ in the intervention group however there were no significant findings between baseline and follow-up $(P=.223)$ in the intervention group. There were no significant findings between the intervention and the control group $(P=.166)$ which has been consistent in our study due to small sample size.

Mediation analysis is a hypothesized causal chain in which one variable affects a second variable, which affects a third variable. The mediator variable mediates a relationship between a predictor (independent variable) and an outcome (dependent variable). TOI scores are most commonly used in clinical trials because it is responsive to change in physical and functional outcomes (Webster, Cella, \& Yost, 2003), therefore we 
utilized TOI scores for our analysis. We obtained the data from the post-intervention results for the mediators since we wanted to determine the effects of either the intervention or standard of care and whether there was a direct or indirect relationship between the group and quality of life. For our study, the mediation analysis predicts a direct relationship between the group and amount of FV consumed $(P<.005)$ and perceived barriers predicts a direct relationship with QoL $(P<.05)$. For all other variables, we cannot confidently predict that participants QoL scores are determined by a nutrition and yoga intervention. For all other variables, we cannot confidently predict that participants TOI scores are determined by the predictor (group) with help of the mediator.

\section{Conclusion}

Although we cannot predict a causal relationship in this study, our findings may suggest the potential benefit of a nutrition and yoga intervention to improve QoL in BCS. Further investigation with a larger sample size and a longer duration is needed to provide evidence-based guidelines for BCS. Even though the results of this intervention did not show significant changes between the control and intervention group there were significant changes within the intervention group from baseline to post-intervention and baseline to follow-up which may indicate a 6-week nutrition and yoga intervention an effective tool to improve QoL in BCS. Limitations of the study include a small sample size, short duration of the intervention, and demographic information indicates a sample population reflective of south Florida therefore we cannot generalize our finding. The strengths of the study were its novelty to assess a nutrition and yoga intervention in BCS. A larger study with longer duration among different racial, ethnic, and economic 
background may be helpful to confirm the benefits of a nutrition and yoga intervention in BCS QoL. Collection of qualitative data to assess which components the participants founds most beneficial would help to enhance the intervention's effectiveness.

The results of this study may serve as a basis for future nutrition interventions aimed at improving quality of life in individuals. The study findings indicate the addition of yoga to a nutrition education program may facilitate lifestyle changes in this population. An increase in physical activity and nutrition knowledge appears to have a direct effect on quality of life. Further investigation is needed, with a larger sample size, to determine which mediators have a direct effect on quality of life. Further studies can then focus on those mediators to create more effective programs to increase physical activity and improve diet quality. 


\section{REFERENCES}

American Cancer Society. Breast Cancer Facts and Figures. (2015). Retrieved April 5, 2016, from

http://www.cancer.org/acs/groups/content/@research/documents/document/acspc046381.pdf

American Cancer Society. Types of breast cancers. (n.d.). Retrieved October 12, 2016, from http://www.cancer.org/cancer/breastcancer/detailedguide/breast-cancer-breastcancer-types

American Institute for Cancer Research. Recommendations for Cancer Prevention. (2016). Retrieved April 5, 2016, from http://www.aicr.org/reduce-your-cancerrisk/recommendations-for-cancer-prevention/?referrer=https://www.google.com/

Ascensão, A., Magalhães, J., Soares, J., Ferreira, R., Neuparth, M., Marques, F., \& Duarte, J. (2006). Endurance exercise training attenuates morphological signs of cardiac muscle damage induced by doxorubicin in male mice. Basic and Applied Myology, 16, 27-35.

Ashrafi, J., Roshan, V. D., \& Mahjoub, S. (2012). Cardioprotective effects of aerobic regular exercise against doxorubicin-induced oxidative stress in rat. African Journal of Pharmacy and Pharmacology, 6(31), 2380-2388.

Bodai, B. I., \& Tuso, P. (2014). Breast cancer survivorship: a comprehensive review of long-term medical issues and lifestyle recommendations. The Permanente Journal, 19(2), 48-79.

Bostean, G., Crespi, C. M., \& Mccarthy, W. J. (2013). Associations among family history of cancer, cancer screening and lifestyle behaviors: A population-based study. Cancer Causes \& Control Cancer Causes Control, 24(8), 1491-1503.

Bower, J. E., Garet, D., Sternlieb, B., Ganz, P. A., Irwin, M. R., Olmstead, R., \& Greendale, G. (2012). Yoga for persistent fatigue in breast cancer survivors. Cancer, 118(15), 3766-3775.

Bower, J. E., Greendale, G., Crosswell, A. D., Garet, D., Sternlieb, B., Ganz, P. A., ... \& Cole, S. W. (2014). Yoga reduces inflammatory signaling in fatigued breast cancer survivors: a randomized controlled trial. Psychoneuroendocrinology, 43, 20-29.

Brenner, D. R., Brockton, N. T., Kotsopoulos, J., Cotterchio, M., Boucher, B. A., Courneya, K. S., . . . Friedenreich, C. M. (2016). Breast cancer survival among young 
women: A review of the role of modifiable lifestyle factors. Cancer Causes \& Control Cancer Causes Control, 27(4), 459-472. doi:10.1007/s10552-016-0726-5

Cancer Facts \& Figures 2015. (n.d.). Retrieved July 26, 2016, from http://www.cancer.org/research/cancerfactsstatistics/cancerfactsfigures2015/

Cao, Y., \& Giovannucci, E. L. (2016, August). Alcohol as a Risk Factor for Cancer. In Seminars in Oncology Nursing (Vol. 32, No. 3, pp. 325-331). WB Saunders.

Carrico, M. Aug 28, 2007. (2015). A Beginner's Guide to the History of Yoga. Yoga for Beginners. Retrieved October 12, 2016, from http://www.yogajournal.com/article/beginners/the-roots-of-yoga/

Catsburg, C., Miller, A. B., \& Rohan, T. E. (2014). Adherence to cancer prevention guidelines and risk of breast cancer. International Journal of Cancer, 135(10), 24442452.

Centers for Disease Control and Prevention: Defining Adult Overweight and Obesity. (2016). Retrieved August 29, 2016, from http://www.cdc.gov/obesity/adult/defining.html

Chan, D. S. M., Vieira, A. R., Aune, D., Bandera, E. V., Greenwood, D. C., McTiernan, A., ... \& Norat, T. (2014). Body mass index and survival in women with breast cancersystematic literature review and meta-analysis of 82 follow-up studies. Annals of Oncology, 1901-1914.

Chaput, J. P., \& Tremblay, A. (2010). Well-being of obese individuals: therapeutic perspectives. Future medicinal chemistry, 2(12), 1729-1733.

Chlebowski, R. T., Blackburn, G. L., Thomson, C. A., Nixon, D. W., Shapiro, A., Hoy, M. K., . . Elashoff, R. M. (2006). Dietary Fat Reduction and Breast Cancer Outcome: Interim Efficacy Results From the Women's Intervention Nutrition Study. JNCI Journal of the National Cancer Institute, 98(24), 1767-1776.

Christifano, D. N., Fazzino, T. L., Sullivan, D. K., \& Befort, C. A. (2016). Diet Quality of Breast Cancer Survivors after a Six-Month Weight Management Intervention: Improvements and Association with Weight Loss. Nutrition and Cancer, 68:8, 13011308.

Christy, S. M., Mosher, C. E., Sloane, R., Snyder, D. C., Lobach, D. F., \& DemarkWahnefried, W. (2011). Long-term dietary outcomes of the FRESH START intervention for breast and prostate cancer survivors. Journal of the American Dietetic Association, 111(12), 1844-1851. 
Côté, J., Delmas, P., Delpierre, C., Sylvain, H., Delon, S., \& Rouleau, G. (2009). Factors related to quality of life in treatment-adherent, successfully treated HIV Patients in France. The Open Nursing Journal, 3(1), 10-17.

Demark-Wahnefried, W., Clipp, E. C., Lipkus, I. M., Lobach, D., Snyder, D. C., Sloane, R., ... \& Kraus, W. E. (2007). Main outcomes of the FRESH START trial: a sequentially tailored, diet and exercise mailed print intervention among breast and prostate cancer survivors. Journal of Clinical Oncology, 25(19), 2709-2718.

Demark-Wahnefried, W., Colditz, G. A., Rock, C. L., Sedjo, R. L., Liu, J., Wolin, K. Y., ... \& Naughton, M. (2015). Quality of life outcomes from the Exercise and Nutrition Enhance Recovery and Good Health for You (ENERGY)-randomized weight loss trial among breast cancer survivors. Breast Cancer Research and Treatment, 154(2), 329-337.

Ferlay J, Soerjomataram I, Dikshit R, et al. Cancer incidence and mortality worldwide: sources, methods and major patterns in GLOBOCAN 2012. International Journal of Cancer. 2015;136:E359-E386.

Ferrini, K., Ghelfi, F., Mannucci, R., \& L. T. (2015). Lifestyle, nutrition and breast cancer: Facts and presumptions for consideration. E-Cancer Journal, 9. Retrieved April 6, 2016.

Finocchiaro, C., Ossola, M., Monge, T., Fadda, M., Brossa, L., Caudera, V., \& De Francesco, A. (2016). Effect of specific educational program on dietary change and weight loss in breast-cancer survivors. Clinical Nutrition, 35(4), 864-870.

Flegal KM, Carroll MD, Kit BK, et al. (2012). Prevalence of obesity and trends in the distribution of body mass index among US adults, 1999-2010. Journal of the American Medical Associaton, 307, 491-497.

Ganz, P. A. (2005). Breast cancer, menopause, and long-term survivorship: critical issues for the 21 st century. The American Journal of Medicine, 118(12), 136-141.

Goncalves AK, Florencio GLD and Maisonnette de Atayde Silva MJ et al (2014) Effects of physical activity on breast cancer prevention: a systematic review Journal of Physical Activity and Health 11 445-454 DOI: 10.1123/jpah.2011-0316

Guenther, P. M., Casavale, K. O., Reedy, J., Kirkpatrick, S. I., Hiza, H. A., Kuczynski, K. J., ... \& Krebs-Smith, S. M. (2013). Update of the healthy eating index: HEI-2010. Journal of the Academy of Nutrition and Dietetics, 113(4), 569-580.

Guenther, P. M., Kirkpatrick, S. I., Reedy, J., Krebs-Smith, S. M., Buckman, D. W., Dodd, K. W., ... \& Carroll, R. J. (2014). The Healthy Eating Index-2010 is a valid and 
reliable measure of diet quality according to the 2010 Dietary Guidelines for Americans. The Journal of nutrition, 3(1), 399-407.

Guenther, P. M., Reedy, J., Krebs-Smith, S. M., \& Reeve, B. B. (2008). Evaluation of the healthy eating index-2005. Journal of the American Dietetic Association, 108(11), 18541864.

Hastert, T. A., Beresford, S. A., Patterson, R. E., Kristal, A. R., \& White, E. (2013). Adherence to WCRF/AICR Cancer Prevention Recommendations and Risk of Postmenopausal Breast Cancer. Cancer Epidemiology Biomarkers \& Prevention, 22(9), 1498-1508.

Howard-Anderson, J., Ganz, P. A., Bower, J. E., \& Stanton, A. L. (2012). Quality of life, fertility concerns, and behavioral health outcomes in younger breast cancer survivors: a systematic review. Journal of the National Cancer Institute. 5(7), 386-405.

Howlader N, Noone AM, Krapcho M, Garshell J, Miller D, Altekruse SF, Kosary CL, Yu M, Ruhl J, Tatalovich Z,Mariotto A, Lewis DR, Chen HS, Feuer EJ, Cronin KA (eds). SEER Cancer Statistics Review, 1975-2012, National Cancer Institute. Bethesda, MD, http://seer.cancer.gov/csr/1975 2012/, based on November 2014 SEER data submission, posted to the SEER web site, April 2015.

Irwin, M. L., Mctiernan, A., Manson, J. E., Thomson, C. A., Sternfeld, B., Stefanick, M. L., . . Chlebowski, R. (2011). Physical Activity and Survival in Postmenopausal Women with Breast Cancer: Results from the Women's Health Initiative. Cancer Prevention Research, 4(4), 522-529.

Johnson, C. B., Davis, M. K., Law, A., \& Sulpher, J. (2016). Shared Risk Factors for Cardiovascular Disease and Cancer: Implications for Preventive Health and Clinical Care of Oncology Patients. Canadian Journal of Cardiology. 32(7), 900-907.

Khankari, N. K., Bradshaw, P. T., Steck, S. E., He, K., Olshan, A. F., Shen, J., . . Gammon, M. D. (2015). Dietary intake of fish, polyunsaturated fatty acids, and survival after breast cancer: A population-based follow-up study on Long Island, New York. Cancer, 121(13), 2244-2252. doi:10.1002/cncr.29329

Kiecolt-Glaser, J. K., Bennett, J. M., Andridge, R., Peng, J., Shapiro, C. L., Malarkey, W. B., ... \& Glaser, R. (2014). Yoga's impact on inflammation, mood, and fatigue in breast cancer survivors: a randomized controlled trial. Journal of Clinical Oncology, 32(10), 1040-1049.

Kirkham, A. A., \& Davis, M. K. (2015). Exercise prevention of cardiovascular disease in breast cancer survivors. Journal of oncology, 2015, 212-225. 
Kushi, L. H., T. Byers, C. Doyle, E. V. Bandera, M. Mccullough, T. Gansler, K. S. Andrews, and M. J. Thun. (2006). "American Cancer Society Guidelines on Nutrition and Physical Activity for Cancer Prevention: Reducing the Risk of Cancer with Healthy Food Choices and Physical Activity." CA: A Cancer Journal for Clinicians, 62(1), 30-67.

Lazarus, R.S., Folaman, S. (1987). Transactional theory and research on emotions and coping. European Journal of Personality, 1, 141-169.

Lee, M., Yun, Y., Park, H., Lee, E., Jung, K., Noh, D. (2014). A web-based selfmanagement exercise and diet intervention for breast cancer survivors: Pilot randomized controlled trial. International Journal of Nursing Stud. 51, 1557-1567.

Lei, Y., Ho, S., Cheng, A., Kwok, C., Lee, C., Cheung K., Lee, R., Loong, H., Yeo, W. (2018). Adherence to the World Cancer Research Fund / American Institute for Cancer Research Guideline is Associated with Better Health-Related Quality of Life Among Chinese Patients with Breast Cancer. Journal of National Comprhensive Cancer Network, 16(3), 275-285.

Li, C. I., Chlebowski, R. T., Freiberg, M., Johnson, K. C., Kuller, L., Lane, D., ... \& Prentice, R. (2010). Alcohol consumption and risk of postmenopausal breast cancer by subtype: the women's health initiative observational study. Journal of the National Cancer Institute, 102(8), 1422-1431.

Ligibel, J. A., Alfano, C. M., Courneya, K. S., Demark-Wahnefried, W., Burger, R. A., Chlebowski, R. T., . . Hudis, C. A. (2014). American Society of Clinical Oncology Position Statement on Obesity and Cancer. Journal of Clinical Oncology, 32(31), 35683574. doi:10.1200/jco.2014.58.4680

Makarem, N., Chandran, U., Bandera, E. V., \& Parekh, N. (2013). Dietary Fat in Breast Cancer Survival. Annu. Rev. Nutr. Annual Review of Nutrition, 33(1), 319-348.

doi:10.1146/annurev-nutr-112912-095300

Makarem, N., Lin, Y., Bandera, E. V., Jacques, P. F., \& Parekh, N. (2015). Concordance with World Cancer Research Fund/American Institute for Cancer Research (WCRF/AICR) guidelines for cancer prevention and obesity-related cancer risk in the Framingham Offspring cohort (1991-2008). Cancer Causes \& Control, 26(2), 277-286.

Martin, L. J., Li, Q., Melnichouk, O., Greenberg, C., Minkin, S., Hislop, G., \& Boyd, N. F. (2011). A randomized trial of dietary intervention for breast cancer prevention. Cancer research, 71(1), 123-133.

Mohammadi, S., Sulaiman, S., Koon, P. B., Amani, R., \& Hosseini, S. M. (2013). Impact of healthy eating practices and physical activity on quality of life among breast cancer survivors. Asian Pacific Journal of Cancer Prevention, 14(1), 481-487. 
National Cancer Institute. Obesity and Cancer Risk. (2012). Retrieved April 19, 2016, from http://www.cancer.gov/about-cancer/causes-prevention/risk/obesity/obesity-factsheet

National Cancer Institute. (2013). Food Attitudes and Behavior Survey. Retrieved February 21, 2017, from Food Attitudes and Behaviors (FAB)

https://cancercontrol.cancer.gov/brp/hbrb/fab/

National Cancer Institute. (2015). Surveillance, Epidemiology, and End Results Program. (n.d.). Retrieved October 12, 2016, from http://seer.cancer.gov/statfacts/html/breast.html

National Comprehensive Cancer Network. (n.d.). Retrieved October 12, 2016, from https://www.nccn.org/professionals/physician_gls/f_guidelines.asp

National Institutes of Health. Physical Activity and Cancer. (2009, July 22). Retrieved November 14, 2016, from https://www.cancer.gov/about-cancer/causesprevention/risk/obesity/physical-activity-fact-sheet\#r7

Patnaik, J. L., Byers, T., DiGuiseppi, C., Dabelea, D., \& Denberg, T. D. (2011). Cardiovascular disease competes with breast cancer as the leading cause of death for older females diagnosed with breast cancer: a retrospective cohort study. Breast Cancer Research, 13(3), 13-22.

Pierce, J. P., Natarajan, L., Caan, B. J., Parker, B. A., Greenberg, E. R., Flatt, S. W., . . . Stefanick, M. L. (2007). Influence of a Diet Very High in Vegetables, Fruit, and Fiber and Low in Fat on Prognosis Following Treatment for Breast Cancer. Journal of Science and Healing, 4(1), 79-80.

Prentice, R. L., Caan, B., Chlebowski, R. T., Patterson, R., Kuller, L. H., Ockene, J. K., ... \& Paskett, E. (2006). Low-fat dietary pattern and risk of invasive breast cancer: The Women's Health Initiative Randomized Controlled Dietary Modification Trial. JAMA, 295(6), 629-642.

Rao, R., Raghuram, N., Nagendra, H., Usharani, M., Gopinath, K., Diwakar, R., . . . Bilimagga, R. (2015). Effects of an integrated yoga program on self-reported depression scores in breast cancer patients undergoing conventional treatment: A randomized controlled trial. Indian Journal of Palliative Care, 21(2), 174. doi:10.4103/09731075.156486

Reeves, M. M., Terranova, C. O., Erickson, J. M., Job, J. R., Brookes, D. S., McCarthy, N., ... \& Winkler, E. A. (2016). Living well after breast cancer randomized controlled trial protocol: evaluating a telephone-delivered weight loss intervention versus usual care in women following treatment for breast cancer. BMC cancer, 16(1), 16:830. 
Renehan AG, Roberts DL, Dive C. Obesity and Cancer: pathophysiological and biological mechanisms. Arch. Physiol. Biochemistry. 2008;114(1):71-83.

Rock, C. L., Flatt, S. W., Wright, F. A., Faerber, S., Newman, V., Kealey, S., \& Pierce, J. P. (1997). Responsiveness of carotenoids to a high vegetable diet intervention designed to prevent breast cancer recurrence. Cancer Epidemiology Biomarkers \& Prevention, 6(8), 617-623.

Romaguera, D., Vergnaud, A., Peeters, P. H., Gils, C. H., Chan, D. S., Ferrari, P., . . Norat, T. (2012). Is concordance with World Cancer Research Fund/American Institute for Cancer Research guidelines for cancer prevention related to subsequent risk of cancer? Results from the EPIC study. American Journal of Clinical Nutrition, 96(1), 150163.

Sadja, J., \& Mills, P. J. (2013). Effects of yoga interventions on fatigue in cancer patients and survivors: a systematic review of randomized controlled trials. Explore: The Journal of Science and Healing, 9(4), 232-243.

Schulz, M., Hoffmann, K., Weikert, C., Nöthlings, U., Schulze, M. B., \& Boeing, H. (2008). Identification of a dietary pattern characterized by high-fat food choices associated with increased risk of breast cancer: the European Prospective Investigation into Cancer and Nutrition (EPIC)-Potsdam Study. British journal of nutrition, 100(05), 942-946.

Siedentopf, F., Utz-Billing, I., Gairing, S., Schoenegg, W., Kentenich, H., Kollak, I. (2013). Yoga for Patients with Early Breast Cancer and its impact on Quality of Life: A Randomized Controlled Trial. Geburtshilfe and Frauenheilkunde, 73(4), 311-317. Siegel R, Ma J, Zou Z, Jemal A (2014) Cancer statistics, 2014. CA Cancer J Clin 64:929.

Sharma, M., Lingam, V. C., \& Nahar, V. K. (2016). A systematic review of yoga interventions as integrative treatment in breast cancer. Journal of Cancer Research and Clinical Oncology, 142(12), 2523-2540.

Song, S., Hwan, E., Moon, H., Noh, D., Lee, J. (2015). Adherence to Guidelines for Cancer Survivors and Health-Related Quality of Life among Korean Breast Cancer Survivors. Nutrients. 7(12), 10307-10319.

Spark, L. C., Reeves, M. M., Fjeldsoe, B. S., \& Eakin, E. G. (2013). Physical activity and/or dietary interventions in breast cancer survivors: a systematic review of the maintenance of outcomes. Journal of Cancer Survivorship, 7(1), 74-82.

Sudarshan, M., Petrucci, A., Dumitra, S., Duplisea, J., Wexler, S., \& Meterissian, S. (2013). Yoga therapy for breast cancer patients: A prospective cohort study. Complementary therapies in clinical practice, 19(4), 227-229. 
Thomson, C. A. (2012). Diet and breast cancer understanding risks and benefits. Nutrition in Clinical Practice, 27(5), 636-650.

Travier, N., Fonseca-Nunes, A., Javierre, C., Guillamo, E., Arribas, L., Peiro, I., Buckland, G., Moreno, F., Urruticoechea, A., Oviedo, G., et al. (2014). Effect of a diet and physical activity intervention on body weight and nutritional patterns in overweight and obese breast cancer survivors. Medical Oncology, 31:783.

Turner, L. B. (2011). A meta-analysis of fat intake, reproduction, and breast cancer risk: An evolutionary perspective. American journal of human biology, 23(5), 601-608.

Wang, D., \& DuBois, R. N. (2010). Eicosanoids and Cancer. National Review of Cancer, 181-193. Retrieved April 26, 2016.

Weaver, K. E., Foraker, R. E., Alfano, C. M., Rowland, J. H., Arora, N. K., Bellizzi, K. M., ... \& Aziz, N. M. (2013). Cardiovascular risk factors among long-term survivors of breast, prostate, colorectal, and gynecologic cancers: a gap in survivorship care?. Journal of Cancer Survivorship, 7(2), 253-261.

Webster, K., Cella, D., \& Yost, K. (2003). The Functional Assessment of Chronic Illness Therapy (FACIT) Measurement System: properties, applications, and interpretation. Health and quality of life outcomes, 1(1), 1:79.

Weichlaus, M., Broom, I., \& G. B. (2011). The molecular contribution of TNF- $\alpha$ in the link between obesity and breast cancer. Oncology Reports, 25(2), 477-483.

doi:10.3892/or.2010.1099

Wiseman M (2012) Food, nutrition, physical activity, and cancer prevention - world cancer research fund (WCRF) Eur J Cancer 48 S14-S14 DOI: 10.1016/S0959$\underline{8049(12) 70759-1}$

World Cancer Research Fund/ American Institute for Cancer Research. 2007. Food, Nutrition, Physical Activity and the Prevention of Cancer: A Global Perspective. AICR. Washington, DC.

Wu, Y., Zhang, D., \& Kang, S. (2013). Physical activity and risk of breast cancer: a meta-analysis of prospective studies. Breast Cancer Research and Treatment, 137(3), 869-882.

Zeng, Y., Huang, M., Cheng, A., Zhou, Y., So, W. (2014). Meta-analysis of the effects of exercise intervention on quality of life in breast cancer survivors. Breast Cancer. 21, 262274. 


\section{Nutrition and Yoga Intervention for Breast Cancer Survivors}

Obtain nutrition knowledge and engage in weekly yoga classes by joining

$$
\text { our study }
$$

We would like to invite you to participate in a study to receive free online nutrition education and yoga classes weekly with a Registered Dietitian/Certified Yoga Instructor from Florida International University

Criteria to be eligible to enroll:

- Women ages 30-60 years of age

- Diagnosed with stage I, II, or IIIc breast cancer

- Cancer-free and post treatment for six months

- Has not participated in regular physical activity within the past three months $(<150$ minutes per week)

- Free of a diagnosed illness that will impact your ability to participate in the study

- Must be able to tolerate and perform yoga in a slightly heated room

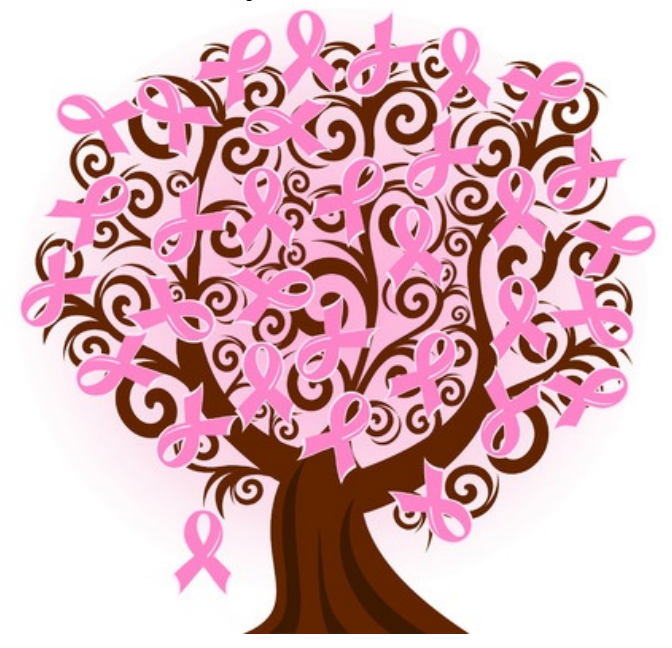

- Must attend at least two yoga classes weekly

- Computer proficient

You will receive six weeks of online nutrition education, emphasizing the dietary guidelines for cancer prevention and recurrence, as well as yoga classes at American Yoga in Deerfield Beach, Florida.

Receive nutrition education and yoga from a Registered Dietitian and Certified Yoga Instructor.

No money will be given as compensation.

If you would like to participate, or for further information,

please contact Tammy Fogarty

PHONE: 561-306-3695

E-MAIL: touel001@fiu.edu 


\section{Appendix 2: Screening Form- Telephone Script}

Hello, this is calling from FIU. Can I speak with Mrs. ?

You received a flyer or social media marketing last week regarding the Nutrition and Yoga Intervention in Breast Cancer Survivors study that we will be conducting at American Yoga in Deerfield Beach. The study is aimed to improve nutrition and physical activity in breast cancer survivor and will be at no cost to you.

1. You indicated that you are interested in enrolling in our research study. Would you like to participate?

Yes No

If No: Thank you for your time Mrs.

2. Are you between 30 and 60 years old?

Yes No

If No: Sorry, you do not qualify for the current study. Thank you for your time Mrs.

3. Have you previously been diagnosed with breast cancer?

Yes No

If No: Sorry, you do not qualify for the current study. Thank you for your time Mrs.

4. Were you diagnosed with stage I, II, or IIIc breast cancer?

Yes No

If No: Sorry, you do not qualify for the current study. Thank you for your time Mrs.

5. Do you participate in regular physical activity, at least 150 minutes per week?

Yes No

If Yes: Sorry, you do not qualify for the current study. Thank you for your time Mrs.

6. Have you been diagnosed with an illness that will impact your ability to participate in the study?

Yes No


If Yes: Sorry, you do not qualify for the current study. Thank you for your time Mrs.

7. Can you tolerate performing yoga in a slightly heated room?

Yes No

If No: Sorry, you do not qualify for the current study. Thank you for your time Mrs.

8. Could you attend at least two yoga classes per week?

Yes No

If No: Sorry, you do not qualify for the current study. Thank you for your time Mrs.

9. Are you comfortable and proficient with using a computer and the Internet?

Yes No

If No: Sorry, you do not qualify for the current study. Thank you for your time Mrs.

10. You will be randomized into one of two study groups: Nutrition only or Nutrition and Yoga. If you are enrolled in the Nutrition only group you will be wait-listed to receive yoga at the end of the study (12 weeks); do you understand and agree to be placed into the group you are randomly assigned to?

Yes No

If No: Sorry, you do not qualify for the current study. Thank you for your time Mrs.

\section{If subject meets all inclusion/exclusion criteria above, then move on:}

You are eligible to enroll in the Nutrition and Yoga Intervention Study. Could you come to American Yoga study site on (date and time) to sign the consent form and fill out the past medical history questionnaire and socio-demographic questionnaire that includes questions related to your age, grade level, race/ethnicity, annual household income? At that time you will be randomized in to the Nutrition only or Nutrition and Yoga group.

If Yes: It has been a pleasure speaking with you Mrs. and I look forward to seeing you on (date and time).

Please provide telephone number, e-mail, and address of American Yoga. 
Appendix 3: Informed Consent

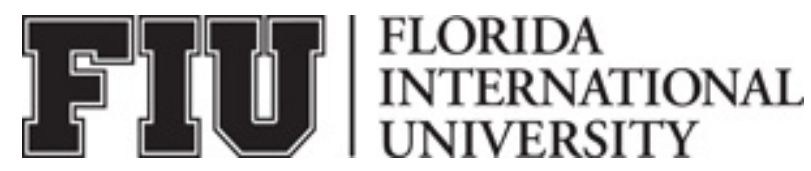

\section{ADULT CONSENT TO PARTICIPATE IN A RESEARCH STUDY Nutrition and Yoga Intervention in Breast Cancer Survivors}

\section{PURPOSE OF THE STUDY}

You are being asked to be in a research study. The purpose of this study is to determine if a nutrition education and yoga intervention is more effective at improving dietary intake and quality of life as compared to receiving dietary education alone.

\section{NUMBER OF STUDY PARTICIPANTS}

If you decide to be in this study, you will one of 22 people in this research study.

\section{DURATION OF THE STUDY}

Your participation will require you to review online nutrition education materials and attend at least two yoga classes per week. It is recommended to spend at least two hours per week with the online materials and at least 150 minutes ( 1 hour 30 minutes) per week attending yoga classes.

\section{PROCEDURES}

If you agree to be in the study, we will ask you to do the following things:

1. Schedule an appointment at American Yoga

2. Before the start of the study you will sign the informed consent, complete screening form, socio-demographic questionnaire, Food Attitudes and Behaviors Survey and FACT-B Quality of Life Index. This meeting will take place at American Yoga and you will be instructed how to complete the assessment tools in-person or online

3. Height and weight will be measured

4. You will be randomly assigned to either the Nutrition and Yoga group or the Nutrition only group.

5. By signing the consent form and completing the assessment tools, you agree to participate in this study for a six-week intervention and a follow-up visit after twelve weeks.

6. For the intervention group: all nutrition education materials will be available at www.nutritionforsurvivors.com. Six learning modules will be available, one for each week of the study. You are required to log-in weekly to view the learning modules which will include written materials, videos, recipes, and links to interactive data such as health quizzes. The control group will receive written materials from the American Cancer Society. 
7. If you are assigned to the Nutrition and Yoga group you are required to attend at least two yoga classes weekly at American Yoga in Deerfield Beach, Florida. You may attend as many classes as you would like however you must attend at least two. If you participate in yoga classes outside of the study, you will be asked to record the dates and times and report these classes to the researcher on a weekly basis. You will also be required to report how often and how much time was spent on the nutrition education modules.

8. At the end of six weeks you will complete the Food Attitudes and Behaviors Survey and FACT-B Quality of Life Index. You can submit the assessment tools online or inperson. Height and Weight will be measured at American Yoga.

9. At the end of twelve weeks you will complete the Food Attitudes and Behaviors Survey and FACT-B Quality of Life Index. You can submit the assessment tools online or in-person. Height and Weight will be measured at American Yoga.

\section{RISKS AND/OR DISCOMFORTS}

The following risks may be associated with your participation in this study: You may experience muscle soreness due to physical activity. This study is considered a minimal risk and participation is voluntary.

\section{BENEFITS}

The following benefits may be associated with your participation in this study: You may experience improvement in nutrition and physical activity knowledge and make better food choices as well as experience improved quality of life. Weight status might also improve.

\section{ALTERNATIVES}

There are no known alternatives available to you other than not taking part in this study. However, any significant new findings developed during the course of the research which may relate to your willingness to continue participation will be provided to you.

\section{CONFIDENTIALITY}

The records of this study will be kept private and will be protected to the fullest extent provided by law. In any sort of report we might publish, we will not include any information that will make it possible to identify a subject. Research records will be stored securely and only the researcher team will have access to the records. However, your records may be reviewed for audit purposes by authorized University or other agents who will be bound by the same provisions of confidentiality.

\section{COMPENSATION \& COSTS}

There will be no monetary compensation provided to you. You will not be responsible for any costs to participate in this study. You will receive nutrition education from a Registered Dietitian and yoga classes from a Certified Yoga Instructor at American Yoga. 


\section{MEDICAL TREATMENT}

Routinely, FIU, its agents, or its employees do not compensate for or provide free care for human subjects in the event that any injury results from participation in a research project. If you become ill or injured as a direct result of participating in this study, contact your regular medical provider. If you have insurance, your insurance company may or may not pay for these costs. If you do not have insurance, or if your insurance company refuses to pay, you will be billed. Funds to compensate for pain, expenses, lost wages and other damages caused by injury are not routinely available.

\section{RIGHT TO DECLINE OR WITHDRAW}

Your participation in this study is voluntary. You are free to participate in the study or withdraw your consent at any time during the study. Your withdrawal or lack of participation will not affect any benefits to which you are otherwise entitled. The investigator reserves the right to remove you without your consent at such time that they feel it is in the best interest.

\section{RESEARCHER CONTACT INFORMATION}

If you have any questions about the purpose, procedures, or any other issues relating to this research study you may contact Dr. Fatma Huffman or Tammy Fogarty, MS, RD at Florida International University, $11200 \mathrm{SW} 8^{\text {th }}$ Street, AHC 5, Miami, FL 33174, Telephone: 305-348-3788 or 561-306-3695, huffmanf@fiu.edu or touel001@fiu.edu.

\section{IRB CONTACT INFORMATION}

If you would like to talk with someone about your rights of being a subject in this research study or about ethical issues with this research study, you may contact the FIU Office of Research Integrity by phone at 305-348-2494 or by email at ori@fiu.edu.

\section{PARTICIPANT AGREEMENT}

I have read the information in this consent form and agree to participate in this study. I have had a chance to ask any questions I have about this study, and they have been answered for me. I understand that I will be given a copy of this form for my records.

Signature of Participant

Printed Name of Participant

Signature of Person Obtaining Consent
Date

Date 
Appendix 4: Demographics Questionnaire

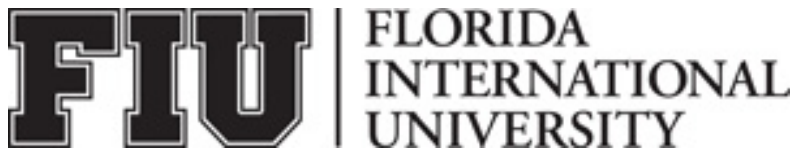

\section{Nutrition and Yoga Intervention on Breast Cancer Survivors Study Demographics Questionnaire}

Please check the option that best describes you.

1. What is your age:
a 30-40
$\square$ 41-50
$\square$ 51-60

2. Please specify your Race/Ethnicity

$\square$ White

$\square$ Hispanic or Latino

$\square$ Black or African-American

$\square$ Asian/ Pacific Islander

$\square$ Other

3. What is the highest degree or level of school you have completed?

$\square$ High school or less

$\square$ More than High School, but not a college graduate

$\square$ Associate degree

$\square$ Bachelor's degree

$\square$ Master's degree

$\square$ Professional degree

$\square$ Doctorate degree

4. What is your marital status?

$\square$ Single, never married

$\square$ Married/Partnered

$\square$ Separated

$\square$ Divorced

$\square$ Widowed

5. What is your employment status?

$\square$ Employed

$\square$ Self-employed

$\square$ Unemployed and looking for work

$\square$ Unemployed but not currently looking for work

$\square$ Retired 
6. What is your current household income?

$\square$ Less than $\$ 25,000$

$\square \$ 25,000$ to $\$ 34,999$

$\square \$ 35,000$ to $\$ 49,999$

$\square \$ 50,000$ to $\$ 74,999$

$\square \$ 75,000$ to $\$ 99,999$

$\square \$ 100,000$ to $\$ 149,999$

$\square \$ 150,000$ or more

$\square$ Prefer not to answer

7. Are you currently a smoker?

$\square$ Yes

$\square$ No 


\section{Appendix 5: Medical History Questionnaire}

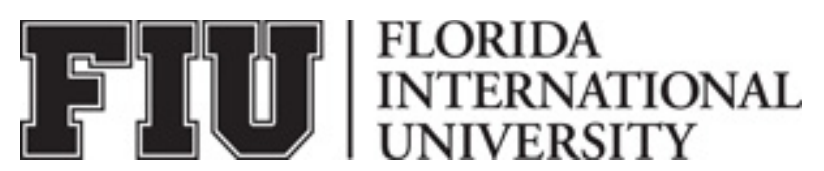

\section{MEDICAL HISTORY QUESTIONNAIRE}

This is your medical history questionnaire to be completed prior to the start of the Nutrition and Yoga Intervention for Breast Cancer Survivors research study. All information will be kept confidential. This information will be used for the evaluation of your health and readiness to begin our yoga program. The form is extensive, but please try to make it as accurate and complete as possible. Please take your time and complete it carefully and thoroughly, and then review it to be certain you have not left anything out. Your answers will help us design a comprehensive program that meets your individual needs.

If you have questions or concerns, we will help you with those after this form is completed. We realize that some parts of the form will be unclear to you. Do your best to complete the form. Your questions will be thoroughly addressed afterwards. It might be helpful for you to keep a written list of questions or concerns as you complete the medical history form.

\section{General Information}

\section{Participant:}

Name

Address

Contact phone numbers

Age

\section{Family Physician and/or Primary Health Care Provider:}

Doctor/Other Phone

Address City

May I send a copy of your consultation to your physician or primary health care provider and consult with them as necessary or to seek approval for your paticipation in the study?

$\square$ Yes No Date: 


\section{MEDICAL HISTORY}

What is your menopausal status:

- Premenopausal

Currently pregnant:

Yes

No

$\square$ Perimenopausal

$\square$ Postmenopausal

Why did your menstrual cycle end?

Natural menopause

Removal of ovaries

Radiation treatment

Hormone-induced menopause

Chemotherapy

Have you ever taken hormone replacement therapy for menopausal symptoms?

No

Yes, but not currently on

Yes, currently on

Have you ever had genetic testing for breast cancer?

$\square$ Yes

BRCA1: Positive Negative

No

BRCA2: Positive Negative

Your past and current diagnoses: select all that apply

$\square$ Breast cancer

$\square$ List any primary cancer other than breasts caner :

$\square$ AIDS/HIV

$\square$ Anemia

Severe anemia

Abnormal bleeding/clotting requiring medication

Other:

$\square$ Autoimmune (lupus, scleroderma)

Please specify:

Breathing or lung

Pulmonary embolism

COPD or emphysema

Asthma requiring medication

Digestive System (stomach, intestines, liver, colon) 
Please specify:

Diabetes

$\square$ Cardiovascular

Chest Pain (angina)

Irregular heart beat (arrhythmia)

Congestive heart failure

Blood clot in leg (Deep Vein Thrombosis)

Heart Attack, please specify when:

High Blood Pressure

Other

$\square$ Kidney, Urinary, or Bladder

Kidney disease on dialysis

Other:

$\square$ Nervous System or brain

Damage to nerves causing numbness/pain/weakness/peripheral neuropathy Blood clot to brain (stroke)

Other:

Osteoporosis

Thyroid

Hyperthyroid

Hypothyroid

Other:

\section{BREAST CANCER HISTORY}

Year of most recent diagnosis:

Type of diagnosis (to either right or left breast)

$\square$ Ductal Carcinoma In situ (DCIS)

$\square$ Ductal carcinoma (invasive or infiltrating)

$\square$ Lobal carcinoma (invasive or infiltrating)

\section{Stage at diagnosis \\ $\square \quad$ In Situ (DCIS) \\ $\square$ Stage I \\ $\square$ Stage II \\ $\square$ Stage III \\ $\square$ Uncertain}


Was the cancer described as inflammatory breast cancer?

$\square$ Yes

$\square$ No

$\square$ Uncertain

Tumor's Estrogen Receptor (ER) status (sometimes called "hormone receptor status")

$\square$ Positive

$\square$ Negative

$\square$ Unclear/Indeterminate results

$\square$ Not Tested

$\square$ Uncertain

Tumor's Progesterone Receptor (PR) status

$\square$ Positive

$\square$ Negative

$\square$ Unclear/Indeterminate results

$\square$ Not Tested

$\square$ Uncertain

Have you ever been diagnosed with lymphedema?

$\square$ Yes

$\square$ No

$\square$ Uncertain

Have you ever had surgery for breast cancer or prevention?

$\square$ Yes

$\square$ No

Select all sites of past surgery:

Month/Year

$\square$ Mastectomy for diagnosed breast cancer

Have you had radiation therapy for breast cancer?

$\square$ Yes

$\square$ No

If yes, when was your last treatment? Please list month and year:

Have you received chemotherapy for breast cancer?

$\square$ Yes

$\square$ No

If yes, when was your last treatment? Please list month and year: 
Appendix 6: Food Attitudes and Behaviors Survey 
SECTION 1 - ATTITUDES AND OPINIONS

1. Please enter TODAY'S DATE here: Q1MM Q1DD Q1YYYY

2. For each statement listed, put an " $X$ " in the box that best indicates how much you personally agree or disagree with that statement. Use the scale of 1 (Strongly Disagree) to 5 (Strongly Agree). If you don't understand a statement or don't have an opinion, please select "DOES NOT APPLY". ("X" ONE BOX ON EACH LINE)

\begin{tabular}{|c|c|c|c|c|c|c|}
\hline & $\begin{array}{l}\text { STRONGLY } \\
\text { DISAGREE } \\
1\end{array}$ & 2 & 3 & 4 & $\begin{array}{l}\text { STRONGLY } \\
\frac{\text { AGREE }}{5}\end{array}$ & $\begin{array}{l}\text { DOES NOT } \\
\text { APPLY }\end{array}$ \\
\hline I enjoy trying new foods Q2A & $\square$ & $\square$ & $\square$ & $\square$ & $\square$ & $\square$ \\
\hline I eat more fruits and vegetables than other people I know & $\square$ & $\square$ & $\square$ & $\square$ & $\square$ & $\square$ \\
\hline $\begin{array}{l}\text { My family or friends would be willing to eat a vegetarian or } \\
\text { vegetable-based meal Q2C }\end{array}$ & $\square$ & $\square$ & $\square$ & $\square$ & $\square$ & $\square$ \\
\hline $\begin{array}{l}\text { I would feel out of place eating fruits and vegetables at a } \\
\text { party where everyone is eating other foods Q2D......................... }\end{array}$ & $\square$ & $\square$ & $\square$ & $\square$ & $\square$ & $\square$ \\
\hline I like sweet foods Q2E & $\square$ & $\square$ & $\square$ & $\square$ & $\square$ & $\square$ \\
\hline I eat enough fruits and vegetables to keep me healthy Q2F.. & $\square$ & $\square$ & $\square$ & $\square$ & $\square$ & $\square$ \\
\hline $\begin{array}{l}\text { I often encourage my family and friends to eat fruits and } \\
\text { vegetables Q2G }\end{array}$ & $\square$ & $\square$ & $\square$ & $\square$ & $\square$ & $\square$ \\
\hline 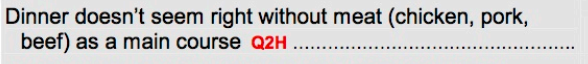 & $\square$ & $\square$ & $\square$ & $\square$ & $\square$ & $\square$ \\
\hline After I eat a meal without meat, I still feel hungry Q21 ............. & $\square$ & $\square$ & $\square$ & $\square$ & $\square$ & $\square$ \\
\hline $\begin{array}{l}\text { My family or friends encourage me to eat fruits and } \\
\text { vegetables Q2J }\end{array}$ & $\square$ & $\square$ & $\square$ & $\square$ & $\square$ & $\square$ \\
\hline My family or friends remind me not to eat junk food Q2K ....... & $\square$ & $\square$ & $\square$ & $\square$ & $\square$ & $\square$ \\
\hline Vegetarians are a bit "different" Q2L & $\square$ & $\square$ & $\square$ & $\square$ & $\square$ & $\square$ \\
\hline $\begin{array}{l}\text { Fast food places offer enough choices of fruits and } \\
\text { vegetables on their menus Q2M }\end{array}$ & $\square$ & $\square$ & $\square$ & $\square$ & $\square$ & $\square$ \\
\hline $\begin{array}{l}\text { Other restaurants (not fast food) offer enough choices of } \\
\text { fruits and vegetables on their menus Q2N }\end{array}$ & $\square$ & $\square$ & $\square$ & $\square$ & $\square$ & $\square$ \\
\hline $\begin{array}{l}\text { Government recommendations for healthy eating are } \\
\text { confusing Q2O }\end{array}$ & $\square$ & $\square$ & $\square$ & $\square$ & $\square$ & $\square$ \\
\hline I like salty foods Q2P & $\square$ & $\square$ & $\square$ & $\square$ & $\square$ & $\square$ \\
\hline I think meals should include some meat $Q 2 Q$ & $\square$ & $\square$ & $\square$ & $\square$ & $\square$ & $\square$ \\
\hline $\begin{array}{l}\text { My family or friends would say something to me if they saw } \\
\text { I was not eating fruits and vegetables Q2R }\end{array}$ & $\square$ & $\square$ & $\square$ & $\square$ & $\square$ & $\square$ \\
\hline $\begin{array}{l}\text { When it comes to food, I'm a creature of habit. I eat the } \\
\text { same things all the time Q2S }\end{array}$ & $\square$ & $\square$ & $\square$ & $\square$ & $\square$ & $\square$ \\
\hline I like spicy foods Q2T & $\square$ & $\square$ & $\square$ & $\square$ & $\square$ & $\square$ \\
\hline $\begin{array}{l}\text { My family and friends often eat fruits and vegetables when } \\
\text { we are together Q2U }\end{array}$ & $\square$ & $\square$ & $\square$ & $\square$ & $\square$ & $\square$ \\
\hline I consider myself to be a spiritual person $\mathrm{Q} 2 \mathrm{~V}$ & $\square$ & $\square$ & $\square$ & $\square$ & $\square$ & $\square$ \\
\hline $\begin{array}{l}\text { I often forget to eat fruits and vegetables because they are } \\
\text { stored out of sight Q2W }\end{array}$ & $\square$ & $\square$ & $\square$ & $\square$ & $\square$ & $\square$ \\
\hline $\begin{array}{l}\text { My family and friends would be annoyed if I encouraged } \\
\text { them to eat fruits and vegetables } 22 X\end{array}$ & $\square$ & $\square$ & $\square$ & $\square$ & $\square$ & $\square$ \\
\hline $\begin{array}{l}\text { I like tart or sour foods (like sauerkraut, pickles, and } \\
\text { grapefruit) Q2Y }\end{array}$ & $\square$ & $\square$ & $\square$ & $\square$ & $\square$ & $\square$ \\
\hline 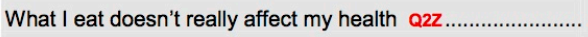 & $\square$ & $\square$ & $\square$ & $\square$ & $\square$ & $\square$ \\
\hline $\begin{array}{l}\text { I am usually among the first of my friends to try new } \\
\text { food/nutrition products Q2AA }\end{array}$ & $\square$ & $\square$ & $\square$ & $\square$ & $\square$ & $\square$ \\
\hline $\begin{array}{l}\text { It's hard for me to eat more vegetables because I don't } \\
\text { know how to prepare them Q2BB..................................... }\end{array}$ & $\square$ & $\square$ & $\square$ & $\square$ & $\square$ & $\square$ \\
\hline I don't understand how someone could be a vegetarian & $\square$ & $\square$ & $\square$ & $\square$ & $\square$ & $\square$ \\
\hline
\end{tabular}




\begin{tabular}{|c|c|c|c|c|c|c|}
\hline & $\begin{array}{l}\text { STRONGLY } \\
\text { DISAGREE } \\
1\end{array}$ & 2 & 3 & 4 & $\begin{array}{c}\text { STRONGLY } \\
\frac{\text { AGREE }}{5}\end{array}$ & $\begin{array}{l}\text { DOES NOT } \\
\text { APPLY }\end{array}$ \\
\hline $\begin{array}{l}\text { I don't pay attention to government recommendations } \\
\text { about what I should eat Q2DD }\end{array}$ & $\square$ & $\square$ & $\square$ & $\square$ & $\square$ & $\square$ \\
\hline I consider myself to be religious Q2EE & $\square$ & $\square$ & $\square$ & $\square$ & $\square$ & $\square$ \\
\hline $\begin{array}{l}\text { It is hard for me to purchase fruits and vegetables in my } \\
\text { neighborhood Q2FF }\end{array}$ & $\square$ & $\square$ & $\square$ & $\square$ & $\square$ & $\square$ \\
\hline $\begin{array}{l}\text { When I eat out, it is easy for me to get fruits and } \\
\text { vegetables Q2GG }\end{array}$ & $\square$ & $\square$ & $\square$ & $\square$ & $\square$ & $\square$ \\
\hline
\end{tabular}

3. For each statement listed, put an " $X$ " in the box that best indicates how much you personally agree or disagree with that statement. Use the scale of 1 (Strongly Disagree) to 5 (Strongly Agree). ("X" ONE BOX ON EACH LINE)

\begin{tabular}{|c|c|c|c|c|c|}
\hline $\begin{array}{l}\text { I don't eat fruits and vegetables as much as I like to } \\
\text { because: }\end{array}$ & $\begin{array}{l}\text { STRONGLY } \\
\text { DISAGREE } \\
1\end{array}$ & 2 & 3 & 4 & $\begin{array}{c}\text { STRONGLY } \\
\frac{\text { AGREE }}{5}\end{array}$ \\
\hline They cost too much Q3A & $\square$ & $\square$ & $\square$ & $\square$ & $\square$ \\
\hline They often spoil before I get a chance to eat them Q3B ....... & $\square$ & $\square$ & $\square$ & $\square$ & $\square$ \\
\hline They take too much time to prepare $\mathrm{Q} 3 \mathrm{C}$ & $\square$ & $\square$ & $\square$ & $\square$ & $\square$ \\
\hline 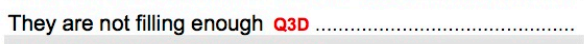 & $\square$ & $\square$ & $\square$ & $\square$ & $\square$ \\
\hline My family doesn't like them Q3E & $\square$ & $\square$ & $\square$ & $\square$ & $\square$ \\
\hline 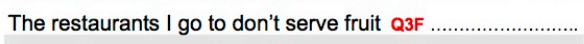 & $\square$ & $\square$ & $\square$ & $\square$ & $\square$ \\
\hline The restaurants I go to don't serve vegetables Q3G .............. & $\square$ & $\square$ & $\square$ & $\square$ & $\square$ \\
\hline 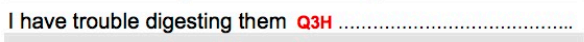 & $\square$ & $\square$ & $\square$ & $\square$ & $\square$ \\
\hline I don't know how to choose fresh fruits and vegetables Q3I. & $\square$ & $\square$ & $\square$ & $\square$ & $\square$ \\
\hline $\begin{array}{l}\text { I just don't think of fruits and vegetables when I'm looking } \\
\text { for something to eat } Q 3 \mathrm{~J}\end{array}$ & $\square$ & $\square$ & $\square$ & $\square$ & $\square$ \\
\hline 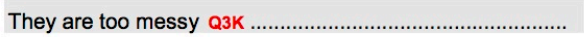 & $\square$ & $\square$ & $\square$ & $\square$ & $\square$ \\
\hline
\end{tabular}

4. About how many CUPS of fruits and vegetables does the government recommend that adults should eat each day? (CHOOSE ONLY ONE ANSWER)

$$
\text { I am really not sure ............. } \square \text { OR }
$$

5. About how many SERVINGS of fruits and vegetables does the government recommend that adults should eat each day? (CHOOSE ONLY ONE ANSWER)

$$
\begin{aligned}
& \text { Q5NS Q5SERV } \\
& \text { I am really not sure ............. } \square \text { OR __ servings per day (WRITE IN NUMBER) }
\end{aligned}
$$

6. When you were growing up, which BEST describes how often you ate fruit? ("X" ONE BOX) Q6

$\begin{array}{lll}\text { More than once a day ...... } \square & \text { More than once a week...... } \square & \text { A few times a month ....... } \square \\ \text { About once a day ............ } \square & \text { Once a week ....................... } \square & \text { Rarely or never ............... }\end{array}$

7. When you were growing up, which BEST describes how often you ate vegetables? ("X" ONE BOX) Q7
More than once a day.....
More than once a week......
A few times a month ....... $\square$
About once a day
Once a week
Rarely or never

8. When you were growing up, which BEST describes your overall physical activity patterns, that is, engaging in activities such as biking, swimming, team sports, brisk walking, etc.? ("X" ONE BOX) Q৪
Not at all active
Fairly active
.
Extremely active
A little active
Very active

\begin{tabular}{|c|c|c|c|c|}
\hline & & & HIIII & \\
\hline & VEGETABLE & FRUIT & ELSE & NOT SURE \\
\hline Black beans Q9A ........ & $\square$ & $\square$ & $\square$ & $\square$ \\
\hline 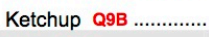 & $\square$ & $\square$ & $\square$ & $\square$ \\
\hline Rice Q9C & $\square$ & $\square$ & $\square$ & $\square$ \\
\hline Grape jelly Q9D .......... & $\square$ & $\square$ & $\square$ & $\square$ \\
\hline Potatoes Q9E............... & $\square$ & $\square$ & $\square$ & $\square$ \\
\hline 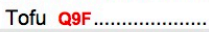 & $\square$ & $\square$ & $\square$ & $\square$ \\
\hline 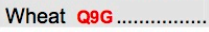 & $\square$ & $\square$ & $\square$ & $\square$ \\
\hline Tomatoes $\mathrm{Q} 9 \mathrm{H} . . . . . . . . . .$. & $\square$ & $\square$ & $\square$ & $\square$ \\
\hline
\end{tabular}

9. For each of the following foods, please indicate whether you consider it to be a vegetable, fruit, or something else. ("X" ONE BOX ON EACH LINE) 
10. What is the name of the CURRENT national campaign to eat fruits and vegetables? ("X" ONE BOX) Q10

Don't know...

$$
\begin{aligned}
& \text { "Fruits and Vegetables: Way to Health" ...... } \square \\
& \text { "Fruits and Veggies: More Matters" ........... }
\end{aligned}
$$

"3 a Day for Healthy Bones".....

SECTION 2 - YOUR HEALTH

11. In general, would you say your health is ... ("X" ONE BOX) Q11
Excellent.
Very Good...
Good......
Fair ........
Poor

12. What is your height and weight without shoes? (WRITE IN)

$\begin{array}{ll}\text { Height: } \quad \stackrel{\text { Q12FT }}{\text { Q12WT }_{\text {Q12IN }} \text { Inches }} \text { Pounds } \\ \text { Weight: } & \text { Pous }\end{array}$

13. How do you describe your weight? ("X" ONE BOX) Q13

UNDERWEIGHT UNDERWEIGHT

OVERWEIGHT

VERY

$\square$

RIGHT WEIGHT

$\square$

14. Are you currently trying to gain weight, lose weight, or neither? ("X" ONE BOX) Q14

GAIN WEIGHT LOSE WEIGHT NEITHER OF THESE

15. How often have you worried about your overall health in the past year? ("X" ONE BOX) Q15
Not at all
A little
Somewhat
Quite a bit..
All the time.

16. How much has worrying about your health led you to change the way you ate in the past year? ("X" ONE BOX) Q16
Not at all ...
A little.
Somewhat
Quite a bit...
All the time.

17. Have you smoked at least 100 cigarettes in your entire life? One hundred cigarettes is equal to $\mathbf{5}$ packs. ("X" ONE BOX) Q17

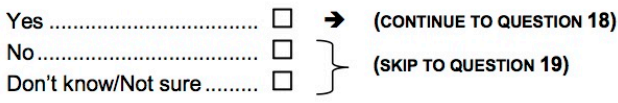

18. Do you now smoke cigarettes every day, some days, or not at all? ("X" ONE BOX) Q18

Every day .......................... $\square$
Some days ........................ $\square$
Not at all .......................... $\square$

SECTION 3 - SHOPPING

19. Who is the primary food shopper(s) in your household? The primary food shopper(s) is the person(s) who

\begin{tabular}{|c|c|c|}
\hline I am (......................... $\square$ & We take turns ................ $\square$ & A parent \\
\hline Spouse or partner.............. $\square$ & We go together................. $\square$ & Someone else.......... \\
\hline
\end{tabular}
does the grocery shopping most often. ("X" ONE BOX) Q19

20. Where does the primary food shopper(s) go grocery shopping? ("X" ALL THAT APPLY)

Large chain grocery store or supermarket Q20A

Natural or organic supermarket Q20B

(such as Whole Foods Market)...

$\square \quad$ Discount superstore (such as Wal-Mart) Q20F.......... Online delivery (such as Peapod or Fresh Direct)

Small local store or corner store Q20C....

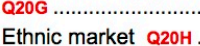

Q

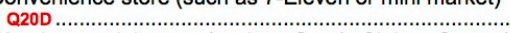

Warehouse club store (such as Sam's Club or Costco)

Q20E .........

$\square$ Farmer's market/co-op $\mathrm{Q} 20$.

Don't know Q20J.... 
21. How often does the primary food shopper(s) go out of their way or make a special effort to go to a particular store to buy fresh or high quality fruits or vegetables? ("X" ONE BOX) Q21
More than once a week.
Every other week..
Every other month..
Yearly or not at all...

Once a week

Once a month

2-3 times a year......

Don't know.

22. In the summer, how often does the primary food shopper(s) get fruits and vegetables from a farmer's market, roadside stand, pick-your-own produce farm or Community Supported Agriculture (CSA)? Q22 ("X" ONE BOX)

More than once a week.. $\square \quad$ Every other week.. $\square \quad$ Less than once a month or not at all....

Once a week

Once a month

Don't know.

\section{SECTION 4 - WHAT YOU EAT AND DRINK}

23. On average, about how many cups of bottled or tap water do you drink each day? ( $8 \mathrm{oz}$. of water is equal to one cup. One standard $16 \mathrm{oz}$. bottle of water equals 2 cups.) ("X" ONE BOX) Q23
None.
$1-3$ cups
4-7 cups
8 or more cups .........

24. How often do you eat pre-washed/ pre-cut fruits and vegetables such as bags of salad, baby carrots, or cut-up fruit? ("X" ONE BOX. DO NOT COUNT FROZEN OR CANNED FRUITS AND VEGETABLES.) Q24

Once a week

Every other week.. $\square$

Every other month.

Yearly or not at all ...

25. How often do you get drinks from coffee places such as Starbucks, Caribou Coffee, and others? ("X" ONE BOX.) Q25

One or more times a day $\square \quad$ Once a week ......... $\square \quad$ Once a month ......... $\square \quad$ 2-3 times a year......

More than once a week .. $\square \quad$ Every other week.. $\quad$ Every other month... $\square$ Yearly or not at all.

26. How many times a week do you usually eat a meal from a fast food restaurant like McDonald's, Burger King, Wendy's, Taco Bell, Pizza Hut, etc.? Consider breakfast, lunch, and dinner. Q26

(WRITE IN NUMBER)

Meals per week

27. How many times a week do you eat a meal while watching television? Consider breakfast, lunch, and dinner.

(WRITE IN NUMBER) _ _ Meals per week

28. How many times a week do you eat dinner sitting around a table with family or friends? Q28

(WRITE IN NUMBER)

Dinners per week

The next two questions ask about cups of fruits and vegetables.

The following boxes provide some examples of how much counts as one cup.

\begin{tabular}{|c|c|c|c|}
\hline $\begin{array}{l}1 \text { cup of fruit } \\
\text { could be: }\end{array}$ & $\begin{array}{l}1 \text { small apple } \\
1 \text { large banana } \\
1 \text { large orange } \\
8 \text { large strawberries } \\
1 \text { medium pear } \\
2 \text { large plums } \\
32 \text { seedless grapes } \\
1 \text { cup }(8 \text { oz.) of } 100 \% \text { juice } \\
1 / 2 \text { cup of dried fruit } \\
1 \text { small wedge of watermelon ( } 1 \text { inch thick) }\end{array}$ & $\begin{array}{l}1 \text { cup of vegetables } \\
\text { could be: }\end{array}$ & $\begin{array}{l}3 \text { broccoli spears, } 5 \text { in. long } \\
1 \text { cup of cooked leafy greens } \\
2 \text { cups of lettuce or raw greens } \\
12 \text { baby carrots } \\
1 \text { medium potato } \\
1 \text { large sweet potato } \\
1 \text { large ear of corn } \\
1 \text { large raw tomato } \\
2 \text { large celery stalks } \\
1 \text { cup of cooked beans }\end{array}$ \\
\hline
\end{tabular}

29. About how many cups of FRUIT (including 100\% pure fruit juice) do you eat or drink each day? Q29 ("X" ONE BOX)

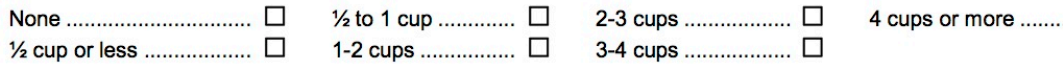


30. About how many cups of VEGETABLES (including $100 \%$ vegetable juice) do you eat or drink each day? ("X" ONE BOX) Q30

None ..................

$1 / 2$ cup or less

$1 / 2$ to 1 cup

$1-2$ cups

2-3 cups

3-4 cups

4 cups or more .........

31. Thinking about yourself, if you were to eat plenty of fruits and vegetables every day, how likely would you be to. .. ("X" ONE BOX ON EACH LINE, USING THE SCALE OF 1, NOT AT ALL LIKELY, TO 5, VERY LIKELY.)

\begin{tabular}{|c|c|c|c|c|c|}
\hline & $\begin{array}{l}\text { NOT AT ALL } \\
\frac{\text { UIKELY }}{1}\end{array}$ & 2 & 3 & 4 & $\begin{array}{l}\text { VERY } \\
\text { UIKELY } \\
5\end{array}$ \\
\hline Have more energy Q31A A......................... & $\square$ & $\square$ & $\square$ & $\square$ & $\square$ \\
\hline 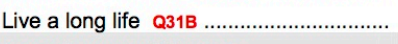 & $\square$ & $\square$ & $\square$ & $\square$ & $\square$ \\
\hline 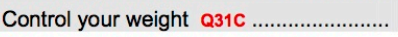 & $\square$ & $\square$ & $\square$ & $\square$ & $\square$ \\
\hline Look better (appearance) Q31D............... & $\square$ & $\square$ & $\square$ & $\square$ & $\square$ \\
\hline 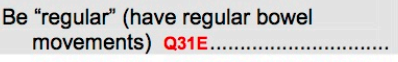 & $\square$ & $\square$ & $\square$ & $\square$ & $\square$ \\
\hline Feel good about yourself $\mathrm{Q} 31 \mathrm{~F} . . . \ldots \ldots \ldots \ldots$ & $\square$ & $\square$ & $\square$ & $\square$ & $\square$ \\
\hline
\end{tabular}

32. The following questions are about what motivates you to eat fruits and vegetables. People have different reasons for eating fruits and vegetables, and we want to know how true the following reasons are for you. Please indicate the extent to which each reason is true for you, using the following 5-point scale. ("X" ONE BOX ON EACH LINE, USING THE SCALE OF 1, NOT TRUE AT ALL, TO 5, VERY TRUE.)

A reason I eat fruits and vegetables is...
Because I want to feel in control of my health Q32A ..........................

\section{SECTION 5 - PHYSICAL ACTIVITY}

33. During the past month, did you participate in any physical activities or exercises such as running, basketball, gardening, dancing, or walking for exercise? ("X" ONE BOX) Q33

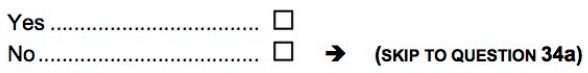

33a. In a typical week, how many days do you do any physical activity or exercise of at least moderate intensity, such as brisk walking, bicycling at a regular pace, and heavy gardening? Moderate-intensity activities make you breathe somewhat harder than normal. ("X" ONE BOX) Q33A

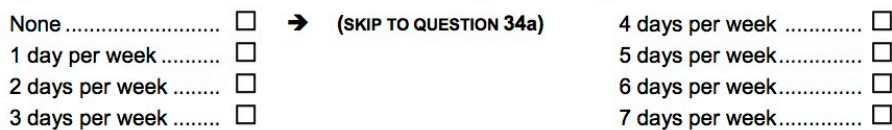


33b. On the days that you do any physical activity or exercise of at least moderate intensity, how long are you typically doing these activities? (WRITE IN NUMBER BELOW).

(WRITE IN NUMBER) $\stackrel{\text { Q33B_HRS }}{\text { Hours }} \stackrel{\text { Q33B_MIN }}{\text { Minutes }}$

\section{SECTION 6 - WHAT YOU ATE IN THE LAST MONTH}

These questions are about the different kinds of foods you ate or drank during the LAST MONTH. Please include meals and snacks eaten at home, at work or school, in restaurants, or any place else.

34a. During the last month, how often did you drink $100 \%$ PURE FRUIT JUICE, such as orange, apple, and grape juices? Do NOT include fruit drinks with added sugar, like Kool-aid, lemonade, Gatorade, fruit punch, and cranberry cocktail. ("X" ONE BOX) Q34A

$\begin{array}{lll}\text { Never........................... } \square & \text { 5-6 times per week........ } \square & 4 \text { times per day................... } \square \\ \text { 1-3 times last month........ } \square & 1 \text { time per day .............. } \square & 5 \text { or more times per day ...... } \square \\ \text { 1-2 times per week.......... } \square & \text { 2 times per day ............ } \square \\ \text { 3-4 times per week........... } \square & \text { 3 times per day ............ }\end{array}$

34b. About how much did you have each time you drank 100\% fruit juice? ("X" ONE BOX) Q34B

Did not drink $100 \%$ fruit juice in the last month ...

$11 / 4$ to 2 cups (10 to 16 ounces)

Less than $3 / 4$ cup (less than 6 ounces)................. $\square \quad$ More than 2 cups (more than 16 ounces)

$3 / 4$ to $1 \frac{1 / 4}{4}$ cup (6 to 10 ounces).

35a. During the last month, how often did you eat FRUIT? Count fresh, frozen, and canned fruit. Do NOT count juices. ("X" ONE BOX) Q35A

$\begin{array}{ll}\text { Never............................ } \square & 5-6 \text { times per week..... } \\ 1-3 \text { times last month........ } & 1 \text { time per day ............ } \\ 1-2 \text { times per week.......... } & \text { 2 times per day .......... } \\ 3-4 \text { times per week.......... } & \text { 3 times per day .......... }\end{array}$

4 times per day....................... 5 or more times per day.......

35b. About how much did you have each time you ate fruit? ("X" ONE BOX) Q35B
Did not eat fruit in the last month

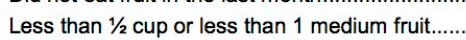
About 1 cup or 1 large fruit More than 1 cup or more than 1 large fruit...

About $1 / 2$ cup or 1 medium fruit

36a. During the last month, how often did you eat lettuce or a green, leafy SALAD, with or without other vegetables? (INCLUDE SPINACH SALADS) ("X" ONE BOX) Q36A

\begin{tabular}{|c|c|c|}
\hline Never.......................... $\square$ & 5-6 times per week....... $\square$ & 4 times per day .................... $\square$ \\
\hline 1-3 times last month........ $\square$ & 1 time per day .............. $\square$ & 5 or more times per day ...... \\
\hline 2 times per week... & 2 times per day. & \\
\hline
\end{tabular}

3-4 times per week.......... $\square \quad 3$ times per day

36b. About how much did you have each time you ate salad? ("X" ONE BOX) Q36B

Did not eat salad in the last month

$\square$ About 2 cups.

About $1 / 2$ cup

About 1 cup

37a. During the last month, how often did you eat FRENCH FRIES, home fries, or hash brown potatoes? ("X" ONE BOX) Q37A

\begin{tabular}{|c|c|c|}
\hline Never.................. $\square$ & 5-6 times per week....... $\square$ & 4 times per day ................... \\
\hline 1-3 times last month........ $\square$ & 1 time per day .............. $\square$ & 5 or more times per day ....... $\square$ \\
\hline $1-2$ times per week......... & 2 times per day ........... & \\
\hline 3-4 times per week ........ $\square$ & 3 times per day & \\
\hline
\end{tabular}

37b. About how much did you have each time you ate French fries, home fries, or hash brown potatoes? ("X" ONE BOX) Q37B

Did not eat fried potatoes in the last month...... $\square$ About 2 cups (large order)........

About 1 cup or less (small order)

About 3 cups or more (Super Size order or more)

About $1 \frac{1}{2}$ cups (medium order) 
38a. During the last month, how often did you have other kinds of non-fried POTATOES? Count baked potatoes, boiled potatoes, mashed potatoes, and potato salad. (INCLUDE YAMS, SWEET POTATOES, REDSKINNED, AND YUKON GOLD POTATOES) ("X" ONE BOX) Q38A

\begin{tabular}{|c|c|c|}
\hline Never.............................. $\square$ & 5-6 times per week....... $\square$ & 4 times per day .................... $\square$ \\
\hline 1-3 times last month......... $\square$ & 1 time per day .............. $\square$ & 5 or more times per day ...... $\square$ \\
\hline 1-2 times per week........... $\square$ & 2 times per day ............ $\square$ & \\
\hline 3-4 times per week........... $\square$ & 3 times per day ............ $\square$ & \\
\hline
\end{tabular}

38b. About how much did you have each time you ate non-fried potatoes? ("X" ONE BOX) Q38B

Did not eat other potatoes in the last month..... $\square \quad 1$ to $1 \frac{1}{2}$ cups ( 1 large potato) .................................

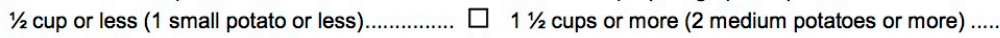

$1 / 2$ to 1 cup (1 medium potato)

39a. During the last month, how often did you eat COOKED DRIED BEANS, such as refried beans, baked beans, bean soup, and pork and beans? Do NOT include green beans. ("X" ONE BOX) Q39A

\begin{tabular}{|c|c|c|}
\hline Never................................ $\square$ & 5-6 times per week....... $\square$ & 4 times per day ...................... $\square$ \\
\hline 1-3 times last month......... $\square$ & 1 time per day ............... $\square$ & 5 or more times per day ...... $\square$ \\
\hline 1-2 times per week........... $\square$ & 2 times per day ............ $\square$ & \\
\hline 3-4 times per week.......... $\square$ & 3 times per day ............ $\square$ & \\
\hline
\end{tabular}

39b. About how much did you have each time you ate COOKED DRIED BEANS? ("X" ONE BOX) Q39B

Did not eat beans in the last month Less than $1 / 2$ cup

$1 / 2$ to 1 cup

$\square \quad 1$ to $1 \frac{1 / 2}{2}$ cup $\square$ More than $1 \frac{1}{2}$ cups.

The next two questions are about other vegetables. The following box provides some examples of how much counts as one cup.

\begin{tabular}{||ll|}
\hline 1 cup of vegetables & \\
could be: & 3 broccoli spears, 5 in. long \\
& 1 cup of cooked leafy greens \\
& 12 baby carrots \\
& 1 large ear of corn \\
1 large raw tomato \\
2 large celery stalks
\end{tabular}

40a. During the last month, how often did you eat OTHER VEGETABLES? Examples of other vegetables include string beans, carrots, corn, peas, tomatoes, collard greens, and broccoli. (DO NOT COUNT LETTUCE SALADS, POTATOES, BEANS, RICE, OR ANYTHING YOU HAVE ALREADY COUNTED.) ("X" ONE BOX) Q40A

Never.

5-6 times per week.......

4 times per day

1-3 times last month

1 time per day

1-2 times per week

2 times per day

3 times per day

40b. About how much did you have each time you ate OTHER VEGETABLES? ("X" ONE BOX) Q40B

Did not eat other vegetables in the last month....

Less than $1 / 2$ cup

.. $\square \quad 1$ to 2 cups

$1 / 2$ to 1 cup..

More than 2 cups

41a. During the last month, how often did you have TOMATO SAUCE, such as spaghetti sauce or pizza with tomato sauce? ("X" ONE BOX) Q41A

$\begin{array}{ll}\text { Never............................. } \square & 5-6 \text { times per week....... } \\ \text { 1-3 times last month........ } \square & 1 \text { time per day .............. } \\ 1-2 \text { times per week........... } & \text { 2 times per day ............ } \\ \text { 3-4 times per week.......... } & \text { 3 times per day ............ }\end{array}$

4 times per day .....................

5 or more times per day.

41b. About how much did you have each time you ate TOMATO SAUCE? ("X" ONE BOX) Q41B

Did not eat tomato sauce in the last month......

About $1 / 4$ cup

About 1 cup

About $1 / 2$ cup

More than 1 cup 
42. Think about the TYPES of fruits and vegetables you eat. Do you tend to eat the same types of fruits and vegetables all year round, or do you tend to eat different types of fruits and vegetables depending on what is "in season"? ("X" ONE BOX) Q42

I tend to eat the same types of fruits and vegetables all year round

I tend to eat different types of fruits and vegetables depending on what is in season...

43. Do you currently consider yourself to be a vegetarian or vegan? ("X" ONE BOX) Q43

$$
\text { Yes....... } \square \quad \text { No ........ } \square \quad \text { Don't know...... } \square
$$

44. Assuming that you want to, how confident are you that you could do each of the following starting this week and continuing for at least 1 month? ("X" ONE BOX ON EACH LINE, USING THE SCALE OF 1, NOT AT ALL CONFIDENT, TO 5, VERY CONFIDENT.)

\begin{tabular}{|c|c|c|c|c|c|c|}
\hline How confident are you that you could... & $\begin{array}{l}\text { NOT AT ALL } \\
\frac{\text { CONFIDENT }}{1}\end{array}$ & 2 & 3 & 4 & $\begin{array}{c}\begin{array}{c}\text { VERY } \\
\text { CONFIDENT }\end{array} \\
\mathbf{5}\end{array}$ & $\begin{array}{l}\text { DOES NOT } \\
\text { APPLY }\end{array}$ \\
\hline 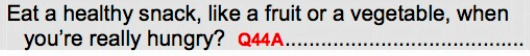 & $\square$ & $\square$ & $\square$ & $\square$ & $\square$ & $\square$ \\
\hline $\begin{array}{l}\text { Eat healthy foods, like fruits or vegetables, when } \\
\text { you are tired? Q44B }\end{array}$ & $\square$ & $\square$ & $\square$ & $\square$ & $\square$ & $\square$ \\
\hline $\begin{array}{l}\text { Eat healthy foods, like fruits or vegetables, when } \\
\text { there are junk foods in your house like chips, } \\
\text { cookies, or candy? }\end{array}$ & $\square$ & $\square$ & $\square$ & $\square$ & $\square$ & $\square$ \\
\hline $\begin{array}{l}\text { Eat fruit instead of cake, cookies, candy, ice cream, } \\
\text { or other sweets for dessert? }\end{array}$ & $\square$ & $\square$ & $\square$ & $\square$ & $\square$ & $\square$ \\
\hline $\begin{array}{l}\text { Eat fruits and vegetables when your family and } \\
\text { friends are eating junk foods like chips, cookies, } \\
\text { or candy? }\end{array}$ & $\square$ & $\square$ & $\square$ & $\square$ & $\square$ & $\square$ \\
\hline $\begin{array}{l}\text { Buy or bring fruits and vegetables to eat at work? } \\
\text { Q44F }\end{array}$ & $\square$ & $\square$ & $\square$ & $\square$ & $\square$ & $\square$ \\
\hline $\begin{array}{l}\text { Snack on fruits and vegetables rather than on junk } \\
\text { foods while watching TV? Q44G }\end{array}$ & $\square$ & $\square$ & $\square$ & $\square$ & $\square$ & $\square$ \\
\hline
\end{tabular}

SECTION 7 - PREFERENCES

45. Next, for each of the fruits listed below, mark the number that best describes how much you like or dislike each type of fruit. ("X" ONE BOX ON EACH LINE, USING THE SCALE OF 1, STRONGLY DISLIKE, TO 5, STRONGLY LIKE.)

\begin{tabular}{|c|c|c|c|c|c|c|}
\hline & $\begin{array}{c}\text { STRONGLY } \\
\frac{\text { DISLIKE }}{1}\end{array}$ & 2 & 3 & 4 & $\begin{array}{l}\text { STRONGLY } \\
\frac{\text { LIKE }}{5}\end{array}$ & $\begin{array}{c}\text { NEVER } \\
\text { TRIED IT }\end{array}$ \\
\hline Apples, applesauce Q45A & $\square$ & $\square$ & $\square$ & $\square$ & $\square$ & $\square$ \\
\hline 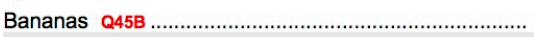 & $\square$ & $\square$ & $\square$ & $\square$ & $\square$ & $\square$ \\
\hline Pears Q45C & $\square$ & $\square$ & $\square$ & $\square$ & $\square$ & $\square$ \\
\hline Watermelon Q45D D & $\square$ & $\square$ & $\square$ & $\square$ & $\square$ & $\square$ \\
\hline 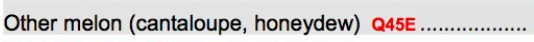 & $\square$ & $\square$ & $\square$ & $\square$ & $\square$ & $\square$ \\
\hline 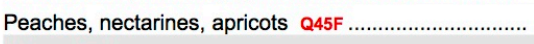 & $\square$ & $\square$ & $\square$ & $\square$ & $\square$ & $\square$ \\
\hline 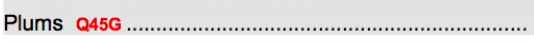 & $\square$ & $\square$ & $\square$ & $\square$ & $\square$ & $\square$ \\
\hline Grapes Q45H & $\square$ & $\square$ & $\square$ & $\square$ & $\square$ & $\square$ \\
\hline Oranges, tangerines Q451 & $\square$ & $\square$ & $\square$ & $\square$ & $\square$ & $\square$ \\
\hline Strawberries Q45J & $\square$ & $\square$ & $\square$ & $\square$ & $\square$ & $\square$ \\
\hline Other berries (blueberries, raspberries, etc.) Q45K........ & $\square$ & $\square$ & $\square$ & $\square$ & $\square$ & $\square$ \\
\hline 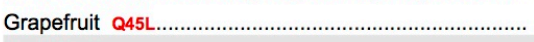 & $\square$ & $\square$ & $\square$ & $\square$ & $\square$ & $\square$ \\
\hline 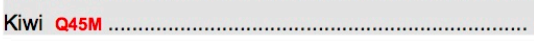 & $\square$ & $\square$ & $\square$ & $\square$ & $\square$ & $\square$ \\
\hline 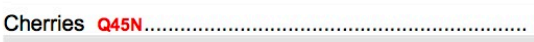 & $\square$ & $\square$ & $\square$ & $\square$ & $\square$ & $\square$ \\
\hline Mango, papaya Q450 & $\square$ & $\square$ & $\square$ & $\square$ & $\square$ & $\square$ \\
\hline Pineapple Q45P & $\square$ & $\square$ & $\square$ & $\square$ & $\square$ & $\square$ \\
\hline Dried fruit (raisins, figs, etc.) Q45Q & $\square$ & $\square$ & $\square$ & $\square$ & $\square$ & $\square$ \\
\hline
\end{tabular}


46. For each vegetable listed below, mark the number that best describes how much you like or dislike each type. ("X" ONE BOX ON EACH LINE, USING THE SCALE OF 1, STRONGLY DISLIKE, TO 5, STRONGLY LIKE.)

\begin{tabular}{|c|c|c|c|c|c|c|}
\hline & $\begin{array}{c}\text { STRONGLY } \\
\frac{\text { DISLIKE }}{1}\end{array}$ & 2 & 3 & 4 & $\begin{array}{l}\text { STRONGLY } \\
\frac{\text { LIKE }}{5}\end{array}$ & $\begin{array}{c}\text { NEVER } \\
\text { TRIED IT }\end{array}$ \\
\hline Tomatoes, tomato sauce Q46A & $\square$ & $\square$ & $\square$ & $\square$ & $\square$ & $\square$ \\
\hline 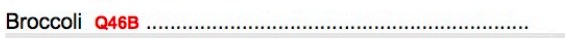 & $\square$ & $\square$ & $\square$ & $\square$ & $\square$ & $\square$ \\
\hline 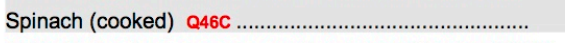 & $\square$ & $\square$ & $\square$ & $\square$ & $\square$ & $\square$ \\
\hline Collards, turnip greens, or mustard greens (cooked) Q46D & $\square$ & $\square$ & $\square$ & $\square$ & $\square$ & $\square$ \\
\hline 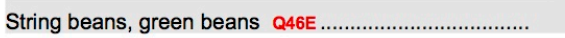 & $\square$ & $\square$ & $\square$ & $\square$ & $\square$ & $\square$ \\
\hline 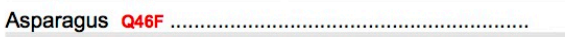 & $\square$ & $\square$ & $\square$ & $\square$ & $\square$ & $\square$ \\
\hline 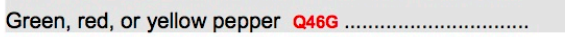 & $\square$ & $\square$ & $\square$ & $\square$ & $\square$ & $\square$ \\
\hline Celery Q46H & $\square$ & $\square$ & $\square$ & $\square$ & $\square$ & $\square$ \\
\hline 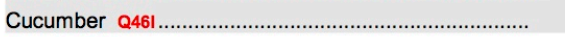 & $\square$ & $\square$ & $\square$ & $\square$ & $\square$ & $\square$ \\
\hline 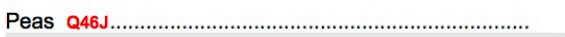 & $\square$ & $\square$ & $\square$ & $\square$ & $\square$ & $\square$ \\
\hline Lima, red, pinto, kidney, lentils, and other beans Q46K & $\square$ & $\square$ & $\square$ & $\square$ & $\square$ & $\square$ \\
\hline 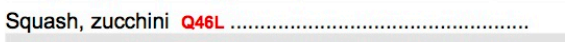 & $\square$ & $\square$ & $\square$ & $\square$ & $\square$ & $\square$ \\
\hline Brussels sprouts Q46M & $\square$ & $\square$ & $\square$ & $\square$ & $\square$ & $\square$ \\
\hline Cauliflower Q46N & $\square$ & $\square$ & $\square$ & $\square$ & $\square$ & $\square$ \\
\hline 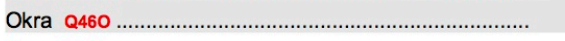 & $\square$ & $\square$ & $\square$ & $\square$ & $\square$ & $\square$ \\
\hline 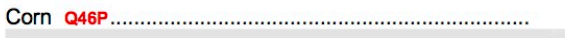 & $\square$ & $\square$ & $\square$ & $\square$ & $\square$ & $\square$ \\
\hline Carrots Q46Q & $\square$ & $\square$ & $\square$ & $\square$ & $\square$ & $\square$ \\
\hline 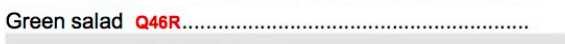 & $\square$ & $\square$ & $\square$ & $\square$ & $\square$ & $\square$ \\
\hline 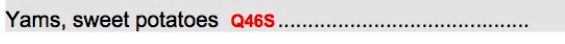 & $\square$ & $\square$ & $\square$ & $\square$ & $\square$ & $\square$ \\
\hline Baked potatoes, mashed potatoes, or potato salad Q46T & $\square$ & $\square$ & $\square$ & $\square$ & $\square$ & $\square$ \\
\hline
\end{tabular}

47. Which, if any, of the following foods do you NOT eat? ("X" ALL THAT APPLY)

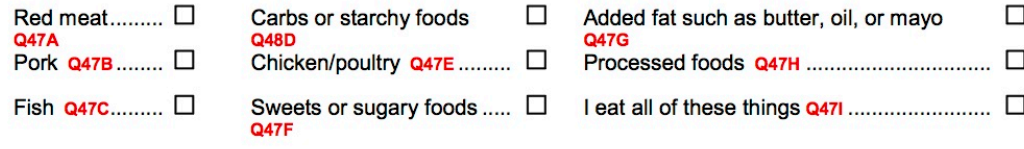

SECTION 8 - GENERAL

Now that you've answered questions about fruits and vegetables, please tell me a little more about yourself and the other things you do.

48. Please tell me whether you consider each statement to be true or false. (" $X$ " ONE BOX FOR EACH STATEMENT)

\begin{tabular}{|c|c|c|}
\hline & $\underline{\text { TRUE }}$ & FALSE \\
\hline I never hesitate to go out of my way to help someone in trouble Q48A & $\square$ & $\square$ \\
\hline I have never intensely disliked anyone Q48B & $\square$ & $\square$ \\
\hline 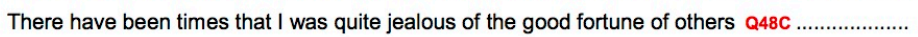 & $\square$ & $\square$ \\
\hline I would never think of letting someone else be punished for my wrong doings Q48D .................. & $\square$ & $\square$ \\
\hline I sometimes feel resentful when I don't get my way Q48E & $\square$ & $\square$ \\
\hline 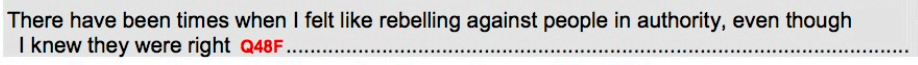 & $\square$ & $\square$ \\
\hline I am always courteous, even to people who are disagreeable Q48G & $\square$ & $\square$ \\
\hline When I don't know something, I don't at all mind admitting it $\mathrm{Q} 48 \mathrm{H}$ & $\square$ & $\square$ \\
\hline I can remember "playing sick" to get out of something $Q 481 . . . \ldots \ldots \ldots . . . . .$. & $\square$ & $\square$ \\
\hline I am sometimes irritated by people who ask favors of me Q48J.. & $\square$ & $\square$ \\
\hline
\end{tabular}


49. Do you have any children or grandchildren under 18 years old living at home with you? ("X" ALL THAT APPLY)

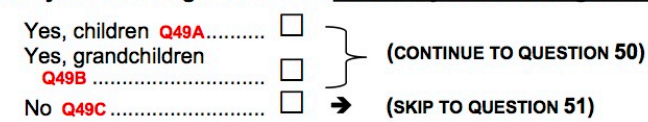

50. Starting with the YOUNGEST child, please list the ages of the three youngest children and/or grandchildren who live at home with you. For any children under 1 year, please write "1".

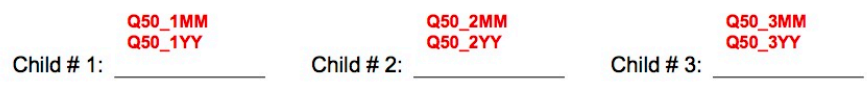

51. On average, how many hours of sleep do you usually get ...
a. On a typical weeknight (Sunday - Thursday)? Q51A (WRITE IN NUMBER) hours/night
b. On a typical weekend night (Friday or Saturday)? Q51B (WRITE IN NUMBER) hours/night

52. IN THE PAST WEEK, how many hours total did you spend using the Internet for personal reasons (not for WOrk)? (ENTER NUMBER OF HOURS IN THE SPACE BELOW. IF YOU DID NOT USE THE INTERNET IN THE PAST WEEK, ENTER “0”.) Q52

$$
\text { (WRITE IN NUMBER) __ \# of hours last week }
$$

53. What is the total number of hours of television you watch...
a. During an average week (add up Monday through Friday)? Q53A.....(WRITE IN NUMBER) Hours
b. During an average weekend (add up Saturday and Sunday)? Q53B .(WRITE IN NUMBER) Hours

54. How often do you do yoga or pilates? ("X" ONE BOX) Q54

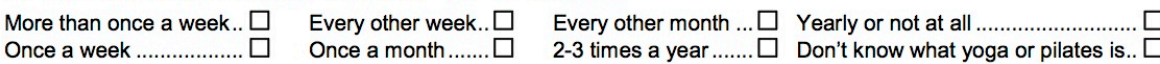

55. FOR WOMEN ONLY: Are you currently pregnant? ("X" ONE BOX) Q55

$$
\text { Yes }
$$

No.

56. Please indicate your gender: ("X" ONE BOX) Q56

$$
\text { Male ............... } \square \quad \text { Female........................ } \square
$$

57. Please indicate your age: ("X" ONE BOX) Q57

$$
\begin{aligned}
& 18-34 \text { years } \\
& 35-54 \text { years } \\
& 55 \text { or older ............. }
\end{aligned}
$$

58. Are you Hispanic or Latino? ("X" ONE BOX) Q58

$$
\begin{aligned}
& \text { Yes } \\
& \text { No } .
\end{aligned}
$$

59. Which one or more of the following would you say is your race? ("X" ALL THAT APPLY) Q59

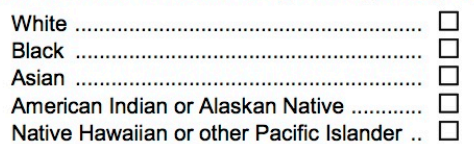

American Indian or Alaskan Native ............

60. Please indicate the highest level of education you have received: ("X" ONE BOX) Q60

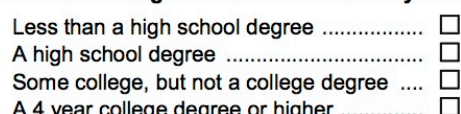

A 4 year college degree or higher

61. Please enter TODAY'S DATE here:

date not captured in data, information previously captured in Q1

THANK YOU! PLEASE RETURN THE SURVEY IN THE ENCLOSED POSTAGE-PAID ENVELOPE. IF THE ENVELOPE IS MISSING, PLEASE SEND TO:

SYNOVATE GLOBAL OPINION PANELS, P.O. BOX 5030, CHICAGO, IL 60680 


\section{Appendix 7: FACT-B Questionnaire}

\section{FACT-B + 4 (Version 4)}

Below is a list of statements that other people with your illness have said are important. Please circle or mark one number per line to indicate your response as it applies to the past 7 days.

\section{PHYSICAL WELL-BEING}

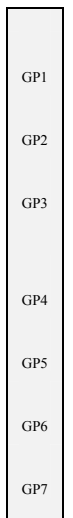

7

\section{SOCIAL/FAMILY WELL-BEING}

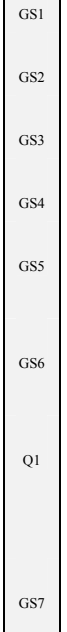

I feel close to my friends

I get emotional support from my family

I get support from my friends.

My family has accepted my illness

I am satisfied with family communication about my

illness

I feel close to my partner (or the person who is my main support)

Regardless of your current level of sexual activity, please answer the following question. If you prefer not to answer it, please mark this box $\square$ and go to the next section.

I am satisfied with my sex life

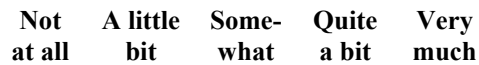

at all bit what a bit much

$\begin{array}{lllll}0 & 1 & 2 & 3\end{array}$

0

0

0

0

0

0

$\begin{array}{ccccc}\text { Not } & \begin{array}{c}\text { A little } \\ \text { at all }\end{array} & \begin{array}{c}\text { Some- } \\ \text { what }\end{array} & \begin{array}{c}\text { Quite } \\ \text { a bit }\end{array} & \begin{array}{c}\text { Very } \\ \text { much }\end{array}\end{array}$




\section{FACT-B + 4 (Version 4)}

Please circle or mark one number per line to indicate your response as it applies to the past 7 days.

\section{EMOTIONAL WELL-BEING}

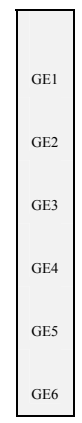

\section{FUNCTIONAL WELL-BEING}

I feel sad.

I feel nervous

I worry about dying
I am satisfied with how I am coping with my illness

I am losing hope in the fight against my illness

I worry that my condition will get worse

I am able to work (include work at home)

My work (include work at home) is fulfilling.

I am able to enjoy life.

I have accepted my illness

I am sleeping well

I am enjoying the things I usually do for fun ...

I am content with the quality of my life right now

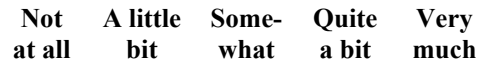

$\begin{array}{lllll}0 & 1 & 2 & 3 & 4\end{array}$

$\begin{array}{lllll}0 & 1 & 2 & 3 & 4\end{array}$

$\begin{array}{lllll}0 & 1 & 2 & 3 & 4\end{array}$

$\begin{array}{lllll}0 & 1 & 2 & 3 & 4\end{array}$

$\begin{array}{lllll}0 & 1 & 2 & 3 & 4\end{array}$

$\begin{array}{lllll}0 & 1 & 2 & 3 & 4\end{array}$

$\begin{array}{lcccc}\text { Not } & \text { A little } & \begin{array}{c}\text { Some- } \\ \text { ahat }\end{array} \text { Quite } & \text { Very } \\ \text { bit bit } & \text { much }\end{array}$

$\begin{array}{lllll}0 & 1 & 2 & 3 & 4\end{array}$

$\begin{array}{lllll}0 & 1 & 2 & 3 & 4\end{array}$

$\begin{array}{lllll}0 & 1 & 2 & 3 & 4\end{array}$

$\begin{array}{lllll}0 & 1 & 2 & 3 & 4\end{array}$

$\begin{array}{lllll}0 & 1 & 2 & 3 & 4\end{array}$

$\begin{array}{lllll}0 & 1 & 2 & 3 & 4\end{array}$

$\begin{array}{lllll}0 & 1 & 2 & 3 & 4\end{array}$




\section{FACT-B + 4 (Version 4)}

Please circle or mark one number per line to indicate your response as it applies to the past 7 days.

\section{ADDITIONAL CONCERNS}

$\begin{array}{ccccc}\begin{array}{c}\text { Not at } \\ \text { all little }\end{array} & \begin{array}{c}\text { Some- } \\ \text { bit }\end{array} & \text { Quite } & \text { Very } \\ \text { what } & \text { a bit } & \text { much }\end{array}$

0

I am self-conscious about the way I dress

0

One or both of my arms are swollen or tender

0

I feel sexually attractive 0

I am bothered by hair loss

\section{0}

I worry that other members of my family might

someday get the same illness I have

I worry about the effect of stress on my illness

I am bothered by a change in weight

I am able to feel like a woman

I have certain parts of my body where I experience pain....

On which side was your breast operation?

$$
\text { Left Right (please circle one) }
$$

Movement of my arm on this side is painful...

I have a poor range of arm movements on this side

My arm on this side feels numb

I have stiffness of my arm on this side

0
0
0
0

$\begin{array}{llll}1 & 2 & 3 & 4 \\ 1 & 2 & 3 & 4 \\ 1 & 2 & 3 & 4 \\ 1 & 2 & 3 & 4\end{array}$


VITA

\section{TAMMY FOGARTY}

Education

1994-1996

A.S., Science

Palm Beach Community College

Boca Raton, Florida

1998-2001

B.S., Dietetics and Nutrition

Florida International University

Miami, Florida

$2001-2005$

M.S., Dietetics and Nutrition

Florida International University

Miami, Florida

Jan 2011- Present

Palm Beach State College

Adjunct Faculty

Oct 2010- Present

Everglades University

Adjunct Faculty

Jan 2013- May 2017 Florida International University

Graduate Teaching Assistant

May 2017- Present Palm Beach State College

Adjunct Faculty

May2017- Present Everglades University

Adjunct Faculty

Nov 2005- Oct 2010 Everglades University

Department Chair of Allied Health/Alternative Medicine

Oct 2004- Nov 2007 Delray Medical Center

Clinical Dietitian 